\title{
Complete genome sequence, lifestyle, and multi- drug resistance of the human pathogen Corynebacterium resistens DSM 45100 isolated from blood samples of a leukemia patient
}

Jasmin Schröder ${ }^{1}$, Irena Maus', Katja Meyer ${ }^{1}$, Stephanie Wördemann ${ }^{1}$, Jochen Blom¹,2, Sebastian Jaenicke ${ }^{1,2}$, Jessica Schneider ${ }^{1,2,3}$, Eva Trost ${ }^{1,3}$ and Andreas Tauch ${ }^{1 *}$

\begin{abstract}
Background: Corynebacterium resistens was initially recovered from human infections and recognized as a new coryneform species that is highly resistant to antimicrobial agents. Bacteremia associated with this organism in immunocompromised patients was rapidly fatal as standard minocycline therapies failed. C. resistens DSM 45100 was isolated from a blood culture of samples taken from a patient with acute myelocytic leukemia. The complete genome sequence of $C$. resistens DSM 45100 was determined by pyrosequencing to identify genes contributing to multi-drug resistance, virulence, and the lipophilic lifestyle of this newly described human pathogen.

Results: The genome of $C$. resistens DSM 45100 consists of a circular chromosome of 2,601,311 bp in size and the 28,312-bp plasmid pJA144188. Metabolic analysis showed that the genome of C. resistens DSM 45100 lacks genes for typical sugar uptake systems, anaplerotic functions, and a fatty acid synthase, explaining the strict lipophilic lifestyle of this species. The genome encodes a broad spectrum of enzymes ensuring the availability of exogenous fatty acids for growth, including predicted virulence factors that probably contribute to fatty acid metabolism by damaging host tissue. C. resistens DSM 45100 is able to use external L-histidine as a combined carbon and nitrogen source, presumably as a result of adaptation to the hitherto unknown habitat on the human skin. Plasmid pJA144188 harbors several genes contributing to antibiotic resistance of C. resistens DSM 45100, including a tetracycline resistance region of the Tet $\mathrm{W}$ type known from Lactobacillus reuteri and Streptococcus suis. The tet( $\mathrm{W})$ gene of pJA144188 was cloned in Corynebacterium glutamicum and was shown to confer high levels of resistance to tetracycline, doxycycline, and minocycline in vitro.

Conclusions: The detected gene repertoire of C. resistens DSM 45100 provides insights into the lipophilic lifestyle and virulence functions of this newly recognized pathogen. Plasmid pJA144188 revealed a modular architecture of gene regions that contribute to the multi-drug resistance of $C$. resistens DSM 45100. The tet( $\mathrm{W})$ gene encoding a ribosomal protection protein is reported here for the first time in corynebacteria. Cloning of the tet( $\mathrm{W})$ gene mediated resistance to second generation tetracyclines in C. glutamicum, indicating that it might be responsible for the failure of minocycline therapies in patients with C. resistens bacteremia.
\end{abstract}

\footnotetext{
* Correspondence: tauch@cebitec.uni-bielefeld.de

${ }^{1}$ Institut für Genomforschung und Systembiologie, Centrum für Biotechnologie, Universität Bielefeld, Universitätsstraße 27, D-33615 Bielefeld, Germany

Full list of author information is available at the end of the article
} 


\section{Background}

The genus Corynebacterium belongs to the taxonomic class Actinobacteria and represents a diverse group of Gram-positive bacteria with a DNA of high $\mathrm{G}+\mathrm{C}$ content, whose members were recognized in a large variety of habitats [1]. The most prominent species of the genus Corynebacterium is the human pathogen Corynebacterium diphtheriae, which is the etiological agent of the acute, communicable disease diphtheria [2]. With the exception of $C$. diphtheriae, the pathogenicity of other corynebacterial species from clinical sources has been underestimated for a long time, as they were often regarded as skin contaminants in human infections [3]. The improved taxonomic recognition of corynebacteria in clinical specimens and the increasing number of case reports associating non-diphtherial species with infections in humans and also in animals has changed this view during the last decade $[4,5]$. In particular, the common skin colonizers Corynebacterium urealyticum and Corynebacterium jeikeium, which both belong to a separate branch in the phylogenetic tree of the genus Corynebacterium [6], were frequently associated with infections in immunocompromised patients. C. urealyticum is primarily recovered from hospitalized elderly individuals and can cause urinary tract infections [7], whereas $C$. jeikeium is associated with a variety of nosocomial infections, for instance with endocarditis after cardiac surgery and with bacteremia in hematological patients $[8,9]$. The majority of clinical isolates assigned to these species displayed a remarkable multi-drug resistance in such a way that only glycopeptide antibiotics remain universally active against these pathogens $[10,11]$. The development of multi-drug resistance in corynebacteria is probably enhanced by the selective pressure occurring in the hospital setting and has tremendous consequences for the successful treatment of human infections, especially in elderly individuals and in immunocompromised patients [12,13].

In 2005, a new multi-drug resistant corynebacterium was isolated from human infections in Japan and named Corynebacterium resistens [14]. Five strains of this bacterium were recovered from blood samples, bronchial aspirates, and abscess specimens and characterized by measuring their susceptibilities to antimicrobial agents. Four strains were obtained from inpatients and revealed high levels of resistance to macrolides, aminoglycosides, tetracyclines, quinolones, and $\beta$-lactams, whereas the fifth isolate was recovered from an outpatient and shown to be susceptible to imipenem and minocycline. The glycopeptides vancomycin and teicoplanin remained universally active against the five isolates. Although the administration of vancomycin is generally regarded as the first choice to eradicate multi-drug resistant corynebacteria, the use of this glycopeptide antibiotic is restricted to methicillin- resistant Staphylococcus aureus (MRSA) in Japan. Minocycline, a second generation tetracycline [15], was administered instead, but this antimicrobial therapy failed and probably contributed to the subsequent death of a patient from sepsis [14].

Experimental data from a polyphasic taxonomic approach revealed that the five clinical isolates were genetically identical and repesent a new subline within the genus Corynebacterium, with the multi-drug resistant species C. urealyticum and C. jeikeium as phylogenetic neighbors [14]. The type strain of this new corynebacterial species is C. resistens DSM 45100 (originally referred to as SICGH 158) that was isolated from a positive blood culture of samples taken from a patient with acute myelocytic leukemia [14]. In this study, we present the complete genome sequence and bioinformatic analysis of C. resistens DSM 45100 providing detailed insights into the lipophilic lifestyle and the virulence factors of this strain. During the sequencing project we recognized that C. resistens DSM 45100 harbors a plasmid that we named pJA144188. The DNA sequences of the chromosome and pJA144188 revealed the molecular mechanisms leading to the extensive antibiotic resistance of $C$. resistens DSM 45100. We detected the tet $(\mathrm{W})$ gene to cause resistance to minocycline and verified its functioning in corynebacteria by expressing the resistance determinant in the susceptible host strain Corynebacterium glutamicum ATCC 13032.

\section{Results and discussion}

\section{Pyrosequencing and annotation of the C. resistens DSM 45100 genome}

The genomic sequence of C. resistens DSM 45100 was determined by a whole-genome shotgun approach with pyrosequencing technology. A quarter of a single run with the Genome Sequencer FLX System and Titanium chemistry yielded 273,646 reads with a total number of $112,335,846$ bases that were assembled into 73 large $(\geq$ 500 bases) contigs and 19 small contigs. Bioinformatic analysis of the sequence assembly indicated that 14 contigs belong to a plasmid that was named pJA144188. The remaining gaps in the chromosome and in plasmid pJA144188 were closed by PCR strategies that were supported by the Consed program [16]. The final assemblies of the DNA sequences yielded a circular chromosome with a size of 2,601,311 bp (Figure 1A) and the 28,312-bp sequence of plasmid pJA144188 (Figure 2). Gene finding and annotation of the C. resistens DSM 45100 genome were performed with the GenDB software system [17] and resulted in the detection and characterization of 2,171 protein-coding regions on the chromosome. Furthermore, three $r r n$ operons were detected with the RNAmmer tool [18], and 50 tRNA genes were predicted by the tRNAscanSE program [19]. Relevant features deduced from the 

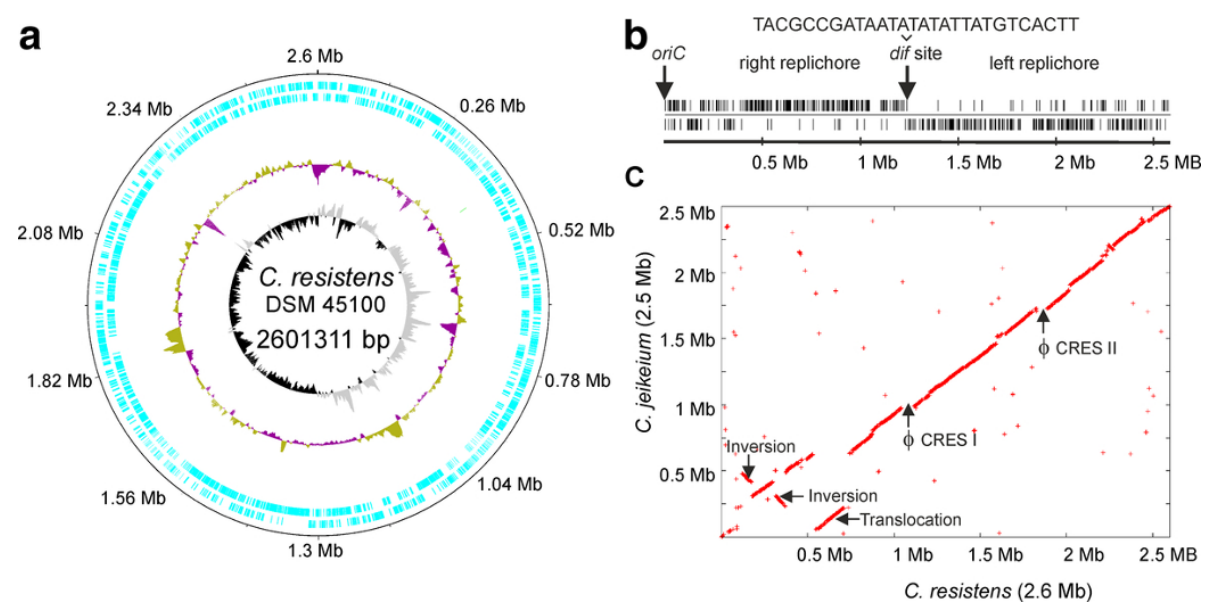

Figure 1 Features of the $C$. resistens DSM 45100 chromosome. (A), Circular representation of the annotated chromosome of C. resistens DSM 45100. The circles represent from the outside: circle 1, DNA base position [Mb]; circle 2, protein-coding regions transcribed clockwise; circle 3, protein-coding regions transcribed anticlockwise; circle 4, G + C content plotted using a 10-kb window; circle 5, G/C skew plotted using a 10-kb window. The plot was generated with the web version of the DNAPlotter tool. (B), Distribution of architecture imparting sequences in the $C$. resistens DSM 45100 chromosome. The distribution of the octamers G(A/T/C)GGGGGA and (T/C)GGGGGAG on the leading and lagging strands of the chromosome is shown. The origin of chromosomal replication (oriC) is marked. The deduced dif locus is located at around $1.23 \mathrm{Mbp}$ of the chromosomal map. The sequence of the 28-bp dif site is shown. (C), Synteny plot between the chromosomes of C. resistens DSM 45100 and C. jeikeium K411. The X-Y plot shows dots forming syntenic regions between the two chromosomes. Each dot represents a C. resistens protein having an ortholog in the C. jeikeium genome, with co-ordinates corresponding to the position of the respective coding region in each genome. The orthologs were identified by reciprocal best BLASTP matches using the predicted amino acid sequences of $C$. resistens proteins. The detected genomic rearrangements are labeled; the positions of the prophages $\Phi C R E S$ I and $\Phi C R E S||$ in the chromosome of C. resistens DSM 45100 are marked.

genome sequence of $C$. resistens DSM 45100 are summarized in Table 1. Plasmid pJA144188 consists of 31 proteincoding regions, of which nine were classified as pseudogenes. All pseudogenes of pJA144188 are remnants of protein-coding regions truncated by the transpositional integration of insertion sequences.

\section{General architecture of the C. resistens DSM 45100 chromosome}

The chromosome of $C$. resistens DSM 45100 revealed the typical features of a corynebacterial genome sequence. A plot of the calculated $\mathrm{G} / \mathrm{C}$ skew $[(\mathrm{G}-\mathrm{C}) /(\mathrm{G}+\mathrm{C})]$ indicated a bi-directional replication mechanism of the C. resistens chromosome (Figure 1A). According to the presence and distribution of conserved DnaA boxes, the origin of replication $(\mathrm{oriC})$ is located downstream of the dnaA coding region [20]. The biased distribution of architecture imparting sequences (AIMS) on the leading and lagging strands of the chromosome indicated the presence of a dif region involved in replication termination [21] at 1,233 $\mathrm{kb}$ on the chromosomal map, dividing the chromosome of $C$. resistens DSM 45100 into two replichores of nearly similar sizes (Figure 1B). A comparative analysis by reciprocal best matches with BLASTP [22] revealed a highly conserved order of orthologous genes between the chromosomes of C. resistens DSM 45100 and C. jeikeium K411 (Figure 1C). Since corynebacteria lack the $\operatorname{rec} B C D$ recombination pathway $[1,23]$, genetic rearrangements are generally rare in the respective genomes, although a moderate reorganization of the chromosomal architecture has been detected in species of the cluster 3 subline of the genus Corynebacterium [24-26]. The chromosomal synteny between C. resistens DSM 45100 and C. jeikeium $\mathrm{K} 411$ is interrupted due to a translocation of a 154-kb DNA region and the inversion of two distinct genomic segments in $C$. resistens (Figure $1 C$ ). As these inversions are part of the right replichore and as intrareplichore inversions are relatively rare [27], we assume that the current chromosomal architecture of $C$. resistens DSM 45100 resulted from a flip-flop of two consecutive inversions. Flip-flop means in this genomic context that the $125-\mathrm{kb}$ central region of an initially inverted 270-kb DNA segment was probably inverted again to maintain the architectural bias in this part of the C. resistens chromosome (Figure 1B).

We therefore examined the gene-strand bias in the chromosome of $C$. resistens DSM 45100, taking into account that gene essentiality is a proposed driving force for the genetic organization in bacterial genomes [28]. In total, $58.7 \%$ of the protein-coding regions of $C$. resistens DSM 45100 are located on the leading strands of the chromosome, revealing a moderate gene-strand bias in this species. A comparative content analysis of predicted protein-coding regions from C. resistens DSM 45100 


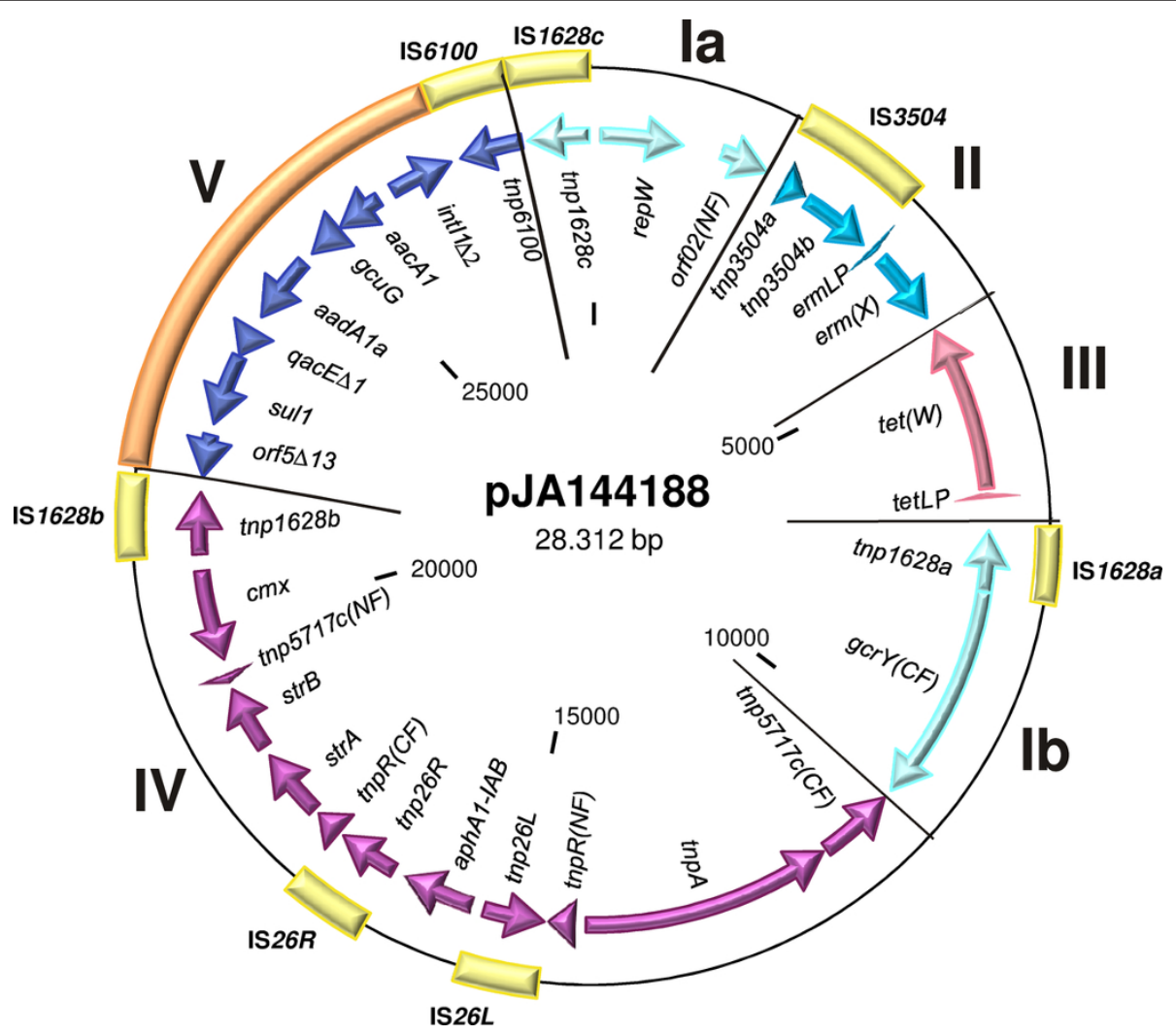

Figure 2 Genetic map of the resistance plasmid pJA144188 from C. resistens DSM 45100. The predicted protein-coding regions of pJA144188 are shown by arrows indicating the direction of transcription. The resistance plasmid can be divided into five distinct DNA modules (I to $V$ ) that are specifically colored. Insertion sequences (IS) are shown as yellow boxes. The position of a class 1 integron is marked by an orange box.

with candidate essential genes detected in the genome of C. glutamicum R by high-density transposon mutagenesis [29] revealed 365 candidate essential genes from C. glutamicum $\mathrm{R}$ having orthologs in the chromosome of $C$. resistens. The majority of these genes $(75.1 \%)$ are located on the leading strands of the $C$. resistens chromosome, with $68.8 \%$ of all candidate essential genes being located on the left replichore, clearly indicating the prominent role of gene essentiality in bacterial gene-strand bias [28]. In

Table 1 Data deduced from the complete genome sequence of $C$. resistens DSM 45100

\begin{tabular}{lll}
\hline Feature & Chromosome & Plasmid pJA144188 \\
\hline Total size (bp) & $2,601,311$ & 28,312 \\
G+C content (\%) & 57.1 & 55.3 \\
No. of protein-coding sequences & 2,171 & 31 \\
Coding density (\%) & 87.9 & 87.4 \\
Average gene length (bp) & 1,053 & 798 \\
No. of rRNAs & $3 \times 16 \mathrm{~S}-23 \mathrm{~S}-5 \mathrm{~S}$ & 0 \\
No. of tRNAs & 50 & 0 \\
No. of CRISPRs & & 0 \\
\hline
\end{tabular}

${ }^{a}$ Abbreviation: Clustered Regularly Interspaced Short Palindromic Repeats the inverted genomic segment of the $C$. resistens chromosome, 46 candidate essential genes are located on the leading strand, whereas 43 candidate essential genes were detected on the lagging strand. This equal distribution of candidate essential genes on the leading and lagging strands might explain why an intra-replichore inversion has been established in the chromosome of $C$. resistens DSM 45100. It suggests furthermore that the orientation of the respective genes has no remarkable impact on the fitness of C. resistens DSM 45100.

Additional breakpoints of synteny between the chromosomes of C. resistens DSM 45100 and C. jeikeium K411 are caused by the presence of genes related to two prophages, named $\varphi$ CRES I and $\varphi$ CRES II (Figure 1C). The genomic segment of $C$. resistens DSM 45100 assigned to $\varphi$ CRES I has a size of about $58.7 \mathrm{~kb}$ and comprises 51 genes, whereas the $\varphi$ CRES II region has a size of about $40.2 \mathrm{~kb}$ and comprises 44 genes, including a transposase gene of an integrated insertion sequence (Figure 3). Both putative prophage genomes share not only a very similar set of protein-coding regions, but also a highly similar order of these genes, suggesting that the respective phages are genetically related (Figure 3 ). 


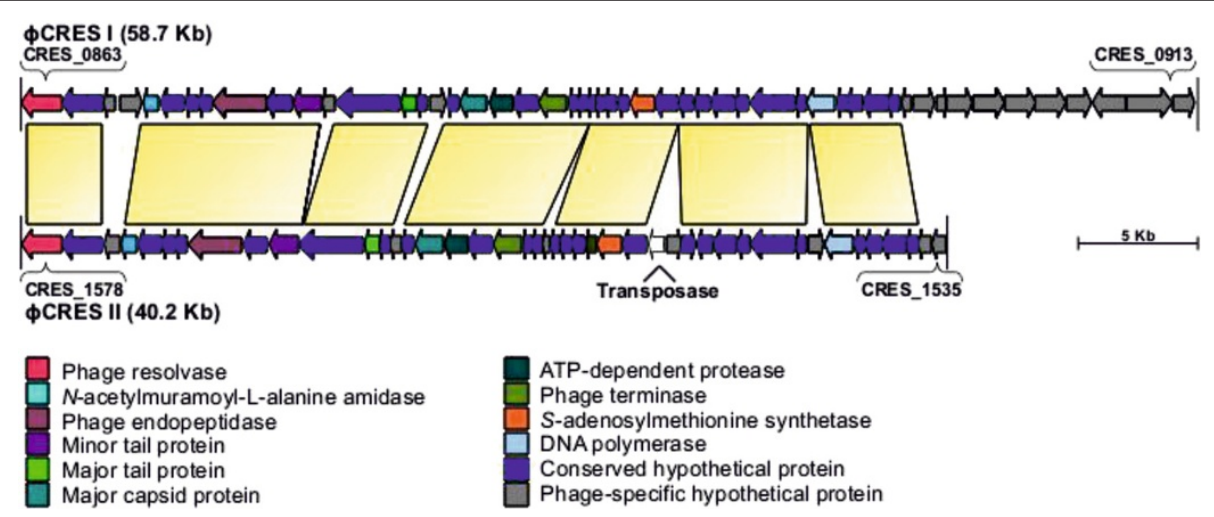

Figure 3 Genetic organizations of prophages in C. resistens DSM 45100. Arrows show genes and their direction of transcription. The color code indicates orthologs in both genomes and is explained in the figure. The integration of an insertion sequence into the genome of $\Phi C R E S \|$ is indicated by the coding region of the respective transposase.

Moreover, a DNA region with 73 clustered regularly interspaced short palindromic repeats (CRISPRs) was detected in the chromosome of $C$. resistens DSM 45100 with the CRISPRFinder tool [30]. The CRISPR locus comprises DNA repeats with a length of $28 \mathrm{bp}$, which are separated by variable 33 -bp spacer sequences. The adjacent genomic region in the chromosome of C. resistens DSM 45100 comprises seven CRISPR-associated genes, named casA-casG. The combination of highly similar CRISPRs and associated cas genes was detected previously in C. jeikeium K411 [25], C. urealyticum DSM 7109 [24], and Nocardia farcinica IFM 10152 [31] and can probably provide acquired resistance to bacteriophages [32].

A comparative content analysis of the predicted proteome of $C$. resistens DSM 45100 with the complete set of proteins encoded in the genomes of C. jeikeium K411 [25], C. urealyticum DSM 7109 [24], and Corynebacterium kroppenstedtii DSM 44385 [26] revealed that the four species belonging to the corynebacterial cluster 3 share 894 orthologous proteins, representing $41.2 \%$ of the predicted proteins from C. resistens DSM 45100 (data not shown). According to this comparative data, C. resistens DSM 45100 contains 563 species-specific genes that probably contribute to the characteristic phenotypic features of this bacterium. In the following sections, we analyze the gene repertoire of C. resistens DSM 45100 in more detail and deduce relevant features regarding the lipophilic lifestyle and the functions involved in virulence and multi-drug resistance of this new human pathogen.

\section{General metabolic features and lipophilic lifestyle of C. resistens DSM 45100}

A bioinformatic reconstruction of the central carbon metabolism of C. resistens DSM 45100 revealed the absence of genes coding for the components of phosphoenolpyruvate:carbohydrate phosphotransferase systems
(PTSs) (Additional file 1). The absence of the respective genes in C. resistens DSM 45100 was supported by TBLASTN searches with reference proteins from other corynebacteria or actinobacteria. PTSs play a major role in uptake and phosphorylation of numerous carbohydrates, as well as in monitoring the bacterial environment to choose alternative carbon sources for growth [33]. Only the $\operatorname{sug} A B C D$ gene cluster encoding a putative sugar transport system of the $A B C$ superfamily was detected in the genome of C. resistens DSM 45100 (Additional file 1). Moreover, the $g l k$ gene encoding glucokinase (EC 2.7.1.2.) and the rbsK gene coding for ribokinase (EC 2.7.1.15) are present in C. resistens DSM 45100, allowing the conversion of "free" sugars into phosphorylated central pathway intermediates. In accordance with this data, the taxonomic description of $C$. resistens indicated that glucose and ribose are catabolized by this species [14]. The $r b s K$ gene is also part of a utilization pathway for the nucleoside uridine [34] that is imported into C. resistens by the major facilitator superfamily transporter UriT and converted to ribose and uracil by an inosine-uridine preferring nucleoside hydrolase (EC 3.2.2.1) encoded by the uriH gene (Additional file 1). Further metabolic analysis of the genome sequence revealed the presence of a complete set of genes involved in glycolysis, gluconeogenesis, and the pentose phosphate pathway. Likewise, the tricarboxylic acid cycle of $C$. resistens DSM 45100 and the glyoxylate bypass, comprising the genes $a c e A$ and $a c e B$, are complete (Additional file 1). This is remarkable as the sucCD genes encoding subunits of succinyl-CoA synthetase (EC 6.2.1.5) are lacking in other sequenced genomes of cluster 3 corynebacteria [24-26]. On the other hand, enzymes catalyzing typical anaplerotic reactions in corynebacterial metabolism are not encoded in C. resistens DSM 45100, including phosphoenolpyruvate carboxylase (EC 4.1.1.31) and pyruvate carboxylase (EC 6.4.1.1). This observation suggests that C. resistens DSM 45100 is dependent on substrates 
for growth that are associated with the complete gluconeogenesis pathway.

The most likely substrates for growth of $C$. resistens are external fatty acids. C. resistens is often assigned to the group of "lipophilic" corynebacteria, whose growth is markedly enhanced by the addition of lipids to the culture medium [3]. This characteristic phenotype per se is a fatty acid auxotrophy that obviously originates from the lack of a fatty acid synthase gene (fas), which is generally responsible for the biosynthesis of fatty acids [35]. To satisfy the essential nutritional requirement for fatty acids as carbon and energy sources, a complete $\beta$-oxidation pathway is encoded in the genome of $C$. resistens DSM 45100 (Additional file 1). Ten $\mathrm{fadD}$ genes encoding acyl-CoA synthetases were identified in the genome of C. resistens DSM 45100, including the fadD1 gene that is involved in mycolic acid biosynthesis [36]. The fadD10 coding region represents a pseudogene as it is disrupted by an insertion sequence. Fatty acyl-CoA synthetases are generally involved in activating free fatty acids to form acyl-CoA of various chain lengths concomitant with the transport into the bacterial cell [37] and are also required for the utilization of endogeneous fatty acids released from membrane lipids [38]. The presence of a large number of orthologs and the amino acid sequence diversity of the fatty acyl-CoA synthetases of C. resistens DSM 45100 might indicate different substrate specificities of these enzymes. Other enzymes involved in the $\beta$-oxidation pathway of C. resistens DSM 45100 are encoded by seven paralogs of $f a d E$ (encoding acyl-CoA dehydrogenase), the bifunctional $f a d B 1$ gene (enoyl-CoA hydratase/hydroxyacyl-CoA dehydrogenase), the monofunctional $f a d B 2$ gene (hydroxyacyl-CoA dehydrogenase), five paralogs of ech $A$ (enoyl-CoA hydratase), and three paralogs of fadA (ketoacyl-CoA thiolase). The predicted amino acid sequences of the paralogous proteins vary substantially in C. resistens DSM 45100, again suggesting diverse substrate specificities of the respective enzymes. Moreover, the $a c x$ gene of $C$. resistens DSM 45100 encodes acylCoA oxidase (EC 1.3.3.6), which catalyzes the desaturation of fatty acyl-CoA thioesters and donates electrons directly to molecular oxygen, thereby producing $\mathrm{H}_{2} \mathrm{O}_{2}$ [39]. The subsequent detoxification of the resulting $\mathrm{H}_{2} \mathrm{O}_{2}$ is catalyzed by catalase (EC 1.11.1.6) encoded by the katA gene of $C$. resistens DSM 45100.

The degradation of modified fatty acyl-CoA esters requires the recruitment of auxiliary enzymes to link their utilization to the main $\beta$-oxidation pathway [39]. The $\mathrm{fadH}$ gene for instance encodes 2,4-dienoyl-CoA reductase (EC 1.3.1.34), which is required for the degradation of unsaturated fatty acids, whose double bond extends from an even-numbered carbon atom. Moreover, the genes prpC and $\operatorname{prpD}$ are involved in the metabolism of propionyl-CoA via the 2-methylcitrate cycle [40]. Propionyl-CoA can result from $\beta$-oxidation of odd-chain fatty acids and is converted to 2-methylisocitrate by the consecutive reactions of 2-methylcitrate synthase (EC 2.3.3.5) encoded by the $\operatorname{prpC}$ gene, and 2-methylcitrate dehydratase (EC 4.2.1.79) encoced by $p r p D$. The last step of this cycle, the cleavage of 2-methylisocitrate to succinate and pyruvate, is catalyzed by 2-methylisocitrate lyase (EC 4.1.3.30) that is not encoded in the genome of C. resistens DSM 45100. Despite the lack of a corresponding $\operatorname{prp} B$ gene to complete the 2-methylcitrate cycle, the oxidation of odd-chain fatty acids by $C$. resistens DSM 45100 seems possible when considering that isocitrate lyase (AceA) might also function as 2-methylisocitrate lyase, as it was demonstrated in $\mathrm{Myco-}$ bacterium tuberculosis [40]. C. resistens DSM 45100 can also channel propionate into the tricarboxylic acid cycle via the enzymatic reactions encoded by the methylcitrate cycle genes (Additional file 1). Propionate is imported into C. resistens DSM 45100 by a monocarboxylic acid transporter encoded by the $m c t C$ gene [41].

The activation of fatty acids to acyl-CoA thioesters is not only the initial step of the $\beta$-oxidation pathway, but also for the biosynthesis of corynomycolic acids [42]. Mycolic acids are major constituents of the corynebacterial cell envelope and synthesized by the polyketide synthase Pks13 [42] and the reductase CmrA [43]. The pks13 coding region of C. resistens DSM 45100 is located in a conserved gene cluster [44], including genes coding for an acyl-CoA carboxylase ( $a c c D 3)$, an acyl-CoA synthetase/ acyl-AMP ligase ( $f a d D 1)$, the envelope lipids regulation factor ElrF (elrF), and two trehalose corynomycol transferases $(c m t B$ and $c m t C)$. A third gene coding for a corynomycolyl transferase $(c m t A)$ is located elsewhere in the chromosome of $C$. resistens DSM 45100. Trehalose corynomycol transferases catalyze the transfer of mycolic acids from trehalose monocorynomycolate on the cell wall arabinogalactan and on another trehalose monocorynomycolate to yield trehalose dicorynomycolate [45].

Another gene cluster involved in fatty acid metabolism of C. resistens DSM 45100 includes genes coding for $\alpha$ and $\beta$ subunits of acyl-CoA carboxylase (accD1 and $a c c B C 1$ ), an acyl-CoA dehydrogenase ( $f a d E 8)$, a putative enoyl-CoA hydratase domain-containing protein $(e c h C)$, a citrate lyase $\beta$-subunit (citE), an acyl-CoA synthetase (fadD5), and a ketoacyl-CoA thiolase (fadA3). The regulatory gene tet $R$ encoding a regulator of the TetR protein family is located in front of the $a c c D 1$ gene and might be involved in the transcriptional control of the complete gene cluster. A similar arrangement of genes is present only in the genomes of the lipophilic species C. jeikeium K411 and Corynebacterium amycolatum SK46, whereas a subset of genes (including a regulatory tet $R$ gene) was found also in the genome of $M$. tuberculosis H37Rv [46]. As most of the proteins encoded in these conserved gene clusters are linked to fatty acid 
catabolism, they might be involved in the activation and subsequent degradation of a hitherto unknown fatty acid substrate.

\section{Amino acid metabolism and utilization of histidine by C. resistens DSM 45100}

According to the genome annotation, all currently known pathways for the biosynthesis of standard proteinogenic amino acids are present in C. resistens DSM 45100 (Additional file 2). The genome sequence of $C$. resistens DSM 45100 contains moreover the agx $T$ gene encoding serineglyoxylate aminotransferase (EC 2.6.1.45) that catalyzes the conversion of L-serine and glyoxylate to 3-hydroxypyruvate and glycine, the $s d a A$ gene encoding L-serine dehydratase (EC 4.3.1.17) involved in the conversion of $\mathrm{L}$-serine to pyruvate and $\mathrm{NH}_{3}$, and the $\operatorname{arcB}$ gene encoding ornithine cyclodeaminase (EC 4.3.1.12) that converts Lornithine to L-proline and $\mathrm{NH}_{3}$ (Additional file 2). Another enzymatic reaction that generates $\mathrm{NH}_{3}$ is carried out by histidine ammonia-lyase (HutH; EC 4.3.1.3). This enzyme catalyzes the first step in the degradation of L-histidine and the product, urocanate, is further metabolized to glutamate and formamid [47]. A complete histidine utilization (hut) pathway was identified in C. resistens DSM
45100 and is represented by the hut gene cluster (Figure $4 \mathrm{~A})$. The products of this gene cluster catalyze the fourstep conversion of L-histidine to L-glutamate (Figure 4B). The first enzymatic reaction of this pathway is catalyzed by $\mathrm{HutH}$, followed by the conversion of the resulting urocanate to 4-imidazolone propanoate by urocanate hydratase (HutU; EC 4.2.1.49). Formiminoglutamate is generated in the third step by imidazolonepropionase (HutI; EC 3.5.2.7) and is finally hydrolyzed into L-glutamate and formamide by formimidoylglutamase (HutG; EC 3.5.3.8).

A comparative analysis of hut gene regions detected in the genus Corynebacterium revealed different genetic organizations of the respective clusters in ten corynebacterial species, with C. resistens DSM 45100 representing a new order of hut genes (Figure 4C). All hut gene clusters contain the hutR gene, which encodes a transcription regulator of the IclR protein family that is probably involved in the transcriptional control of histidine utilization in corynebacteria. It is remarkable that the majority of corynebacterial species harboring a hut gene cluster are in some way associated with the urogenital tract. Corynebacterium glucuronolyticum, Corynebacterium tuberculostearicum, and Corynebacterium pseudogenitalium were isolated from the

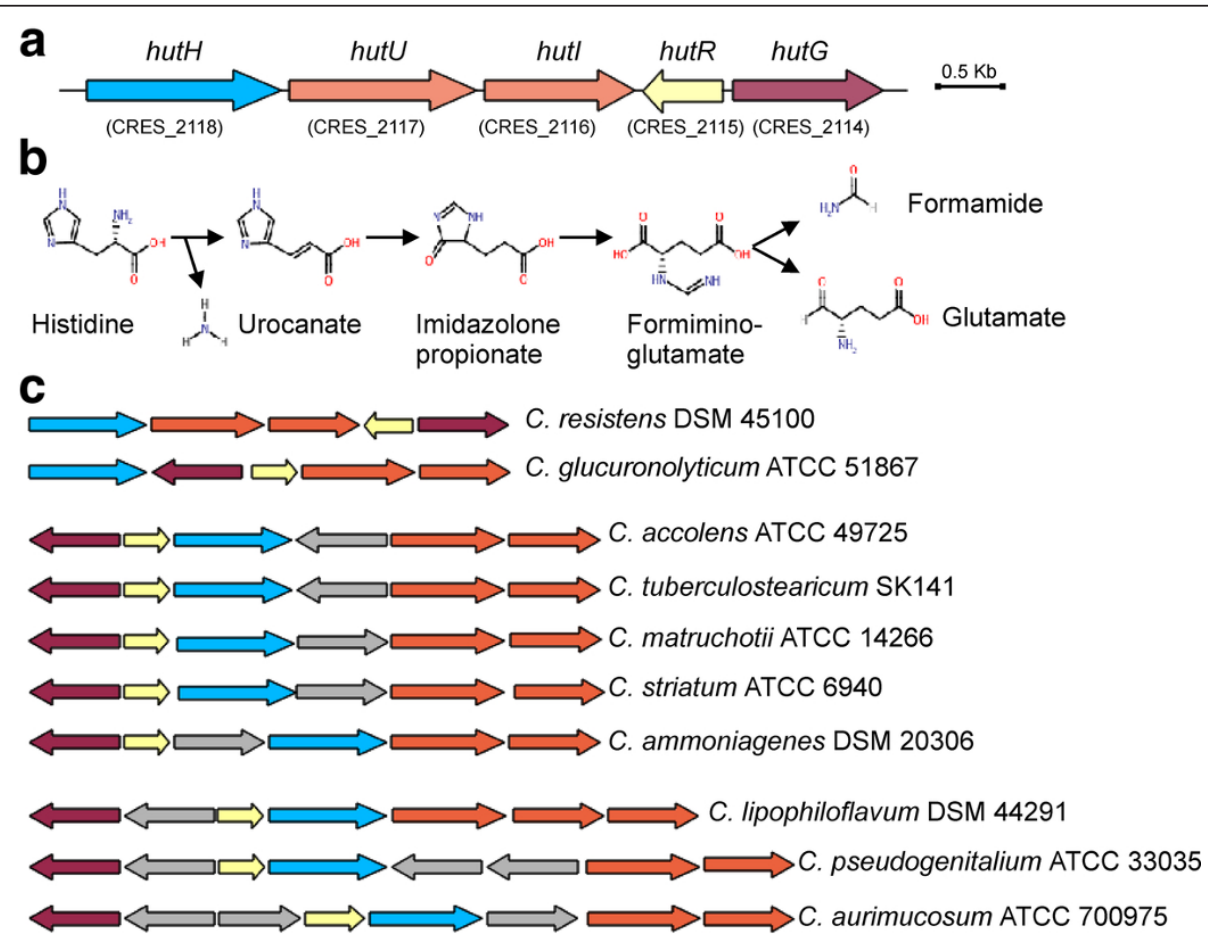

Figure 4 Genetic organizations of hut gene regions in C. resistens DSM 45100 and other corynebacteria. (A), Map of the hut gene region of $C$. resistens DSM 45100. Arrows represent hut genes and indicate their direction of transcription. The hut genes are labeled with names and identifiers. (B), Metabolic pathway for the catabolism of L-histidine. Enzymes of the four-step hut pathway are: HutH, histidine ammonia-lyase; HutU, urocanate hydratase; Hutl, imidazolonepropionase; HutG, formimidoylglutamase; HutR, transcriptional regulator of the IcIR superfamily. (C), Comparative analysis of hut gene regions in corynebacterial species. Genes with similar color participate in the same enzymatic step of the pathway. Additional genes present in the respective genomic regions are shown in grey. 
urogenital tract of males and females [48-50], whereas Corynebacterium lipophiloflavum was isolated from bacterial vaginosis [51]. Black-pigmented Corynebacterium aurimuсоsum isolates derive from vaginal swabs and probably cause spontaneous abortion [52]. Indeed, variable amounts of L-histidine are present in the human vaginal fluid [53] and might be used by these bacteria as a combined nitrogen and carbon source for growth. C. resistens DSM 45100 might also use L-histidine as a carbon and/or nitrogen source, thus compensating for the restricted availability of carbohydrates due to the strict lipophilic lifestyle. The natural habitat of $C$. resistens is currently unknown, although the utilization of L-histidine by the enzymatic machinery of the hut pathway points to a colonization of the human inguinal or perineal regions, thereby living in close proximity to the human genital tract. This hypothesis is consistent with previous microbiological studies that recovered lipophilic corynebacteria predominantly from the axillary, inguinal, and perineal areas of the human body [54]. These sites of the human body are characterized by an elevated moisture of the skin in conjunction with a substantial formation of hydrolipid films, which are composed of triacylglycerides, free fatty acids, ceramides, cholesterol, and cholesterol esters. These compounds are appropriate carbohydrate substrates for the growth of lipophilic corynebacteria. Additional experimental evidence to support the hypothesis that $C$. resistens is a colonizer of the inguinal and/or perineal areas of the human body is currently lacking, as no $16 \mathrm{~S}$ rDNA sequences of $C$. resistens were detected in the course of the human microbiome project already covering several body sites, including the human urogenital tract [55].

\section{Detection of candidate virulence factors in the genome of C. resistens DSM $\mathbf{4 5 1 0 0}$}

To better understand the pathogenic potential of $C$. resistens DSM 45100, the genome sequence was furthermore screened for genes encoding candidate virulence factors, which in principle should be part of the exoproteome of this species. To estimate the number of secreted proteins encoded by C. resistens DSM 45100, the first 70 amino acid residues of each predicted protein were used to search for amino-terminal signal peptides with SignalP 4.0 [56]. In this way, a total number of 254 proteins were identified to be potentially secreted by C. resistens DSM 45100 . However, it has to be considered that proteins with signal peptides might be destined for the integration into the cytoplasmic membrane and therefore contain membrane-spanning domains [57]. A total number of 258 predicted proteins with membrane-spanning domains were detected by the TMHMM tool [58], and the combined feature of signal peptides and membrane-spanning domains was found in a subset of 78 proteins of $C$. resistens DSM 45100. The remaining proteins were screened for predicted functions probably related to the virulence of $C$. resistens DSM 45100 (Table 2).

C. resistens DSM 45100 encodes two cell surface protein precursors, named SurA and SurB, which contain carboxyterminal sorting (LPxTG) signals recognized by sortase transpeptidase. The housekeeping sortase of $C$. resistens DSM 45100 (SrtC) is most likely responsible for anchoring these LPxTG-containing proteins to the corynebacterial cell wall [59]. The carboxyterminal part of the SurB protein contains a remarkable tandem repeat region with the consensus sequence PGTTTPGTTA that is present 13 times with only moderate variations in the amino acid sequence. Additional repeat regions with the consensus sequences WATVNPDGS or VVVTYPDGS are present in the central region of the cell surface protein. The SurB protein of C. resistens DSM 45100 is thus structurally similar to the alpha $C$ protein-antigen of group B streptococci containing large tandem repeating units [60]. Variations of the number of tandem repeat regions of the alpha C protein affected the pathogenicity of group B streptococci [61], and the structural variations of the bacterial cell surface conferred protective immunity against the host defense [62].

Another structural component of the cell surface of C. resistens DSM 45100 is an adhesive pilus of the SpaABC type (Table 2). Cell-surface pili are important virulence factors that enable pathogens to adhere to specific host tissues and to modulate host immune response [63]. The SpaABC pilus of C. resistens DSM 45100 is covalently anchored to the corynebacterial cell wall by the pilin-specific sortases SrtA and SrtB via a transpeptidylation mechanism [59]. The adhesive pilus of C. resistens DSM 45100 consists of three pilin subunits encoded by the

\section{Table 2 Candidate virulence factors detected in the} chromosome of C. resistens DSM 45100

\begin{tabular}{|c|c|c|}
\hline Identifier & Gene & $\begin{array}{l}\text { Predicted protein function (and putative role in } \\
\text { virulence) }\end{array}$ \\
\hline CRES_2101 & surA & surface protein (cell surface variation) \\
\hline CRES_0606 & surB & surface protein (cell surface variation) \\
\hline CRES_0405 & spaA & major pilin subunit of the SpaABC pilus (adhesion) \\
\hline CRES_0407 & $s p a B$ & minor pilin subunit of the SpaABC pilus (adhesion) \\
\hline CRES_0408 & spaC & tip protein of the SpaABC pilus (adhesion) \\
\hline CRES_1049 & rpfl & $\begin{array}{l}\text { resuscitation-promoting factor-interacting protein } \\
\text { (adhesion) }\end{array}$ \\
\hline CRES_0767 & $\mathrm{CW} / \mathrm{H}$ & cell wall-associated hydrolase (adhesion) \\
\hline CRES_0700 & choD & cholesterol oxidase (oxidation of cholesterol) \\
\hline CRES_1191 & asa & alkaline ceramidase (hydrolysis of ceramides) \\
\hline CRES_0207 & lips1 & lipase of the LIP superfamily (lipolytic activity) \\
\hline CRES_1004 & lips2 & lipase of the LIP superfamily (lipolytic activity) \\
\hline CRES_2090 & lipS3 & lipase of the LIP superfamily (lipolytic activity) \\
\hline CRES_0539 & $\operatorname{sgnH}$ & $\begin{array}{l}\text { esterase of the SGNH-hydrolase superfamily } \\
\text { (lipolytic activity) }\end{array}$ \\
\hline
\end{tabular}


spaABC genes. The spaA gene encodes the major pilin of the pilus shaft, whereas the spaB and spaC genes code for minor pilins located at the base and at the tip of the pilus, respectively. The homologous pilus structure of $C$. diphtheriae NCTC 13129 can mediate the adhesion of the pathogen to human pharyngeal epithelial cells, which is a crucial step during infection [64].

Further candidate virulence factors that may support the adhesion of C. resistens DSM 45100 to host cells are encoded by the rpfI and $c w l H$ genes (Table 2). The deduced proteins revealed amino acid sequence homology to DIP1281 and DIP1621 from C. diphtheriae NCTC 13129 , respectively. The rpfI gene encodes a resuscitationpromoting factor-interacting protein that forms complexes with lytic transglycosylases (resuscitation-promoting factors) at the septum of dividing bacteria [65]. C. resistens DSM 45100 encodes two resuscitation-promoting factors, named RpfA and RpfB, which may interact with the RpfI protein. The homologous gene product DIP1281 was shown to be crucial for adhesion and colonization of host epithelial cells [66]. Defined DIP1281 mutant cells of $C$. diphtheriae completely lacked the ability to adhere to host cells and to invade these [66]. Due to the interaction of RpfI with resuscitation-promoting factors, it is probably involved in the organization of the outer surface layer of the pathogen and might thereby impair the efficiency of adhesion. The $c w l H$ gene of $C$. resistens DSM 45100 encodes a cell wall-associated hydrolase with a carboxyterminal domain similar to proteins belonging to the NlpC/P60 family [67]. The targeted disruption of the homologous DIP1621 gene in C. diphtheriae led to decreased adherence to epithelial cells; but the exact function of this protein remains unknown so far [68].

Among the candidate virulence factors detected in C. resistens DSM 45100 is also a secreted cholesterol oxidase encoded by the $c h o D$ gene (Table 2). The deduced ChoD protein is a putative membrane-damaging toxin, probably causing the enzymatic oxidation of macrophage membrane cholesterol [69]. Cholesterol oxidase is an important cytolytic factor for Rhodococcus equi as its presence was accompanied by intracellular survival of this pathogen, whereas a non-virulent strain lacking this enzyme was largely eliminated from the macrophages [69]. Likewise, a choD mutant of $M$. tuberculosis was attenuated in peritoneal macrophages, whereas no attenuation was observed when the same strain was complemented with an intact $c h o D$ gene [70]. The oxidation of membrane cholesterol might lead to total disorganization of the eukaryotic cell membrane [71], supporting the release of substrates for other enzymes involved in fatty acid metabolism of a pathogen. Another enzyme representig a candidate virulence factor of $C$. resistens DSM 45100 is the secreted alkaline ceramidase encoded by the as $a$ gene (Table 2). Ceramidases hydrolyze the amide bond in ceramides, which results in the release of free fatty acids and sphingosine [72]. Sphingolipids are components of eukaryotic cell membranes, and hence they are putative targets for acquiring fatty acids by means of eukaryotic membrane damage. Moreover, the release of sphingosine by alkaline ceramidases is known for instance to attenuate the activity of macrophages [73].

C. resistens DSM 45100 can also generate free fatty acids from the host tissue by secreting lipolytic enzymes (Table 2). Three secreted lipases of the LIP superfamily containing enzymes with broad lipolytic activities are encoded in the genome of $C$. resistens DSM 45100 by lipS1, lipS2, and lipS3. These enzymes may thus contribute to the generation of free fatty acids from precursor molecules such as triacylglycerol. The prototype enzymes of the LIP superfamily were studied in Candida albicans, where these lipases are expressed and secreted during the infection cycle of this pathogen and may contribute to the persistence and virulence of $C$. albicans in human tissue [74]. The $s g n H$ gene of $C$. resistens DSM 45100 was also classified as a candidate virulence factor (Table 2). It encodes a secreted hydrolase of the SGNH superfamily, which is a group of enzymes that hydrolyze ester bonds in lipids [75]. SGNH enzymes have little sequence homology to other lipases and are characterized by the four invariant catalytic residues serine, glycine, asparagine, and histidine. Due to a flexible active site that appears to change conformation with the presence of different substrates, SGNH esterases and lipases are hydrolytic enzymes with multifunctional properties, such as broad substrate specificities [75]. In summary, numerous candidate virulence factors of C. resistens DSM 45100 are obviously linked to the strict lipophilic lifestyle of this species by providing essential nutrients for bacterial growth.

\section{The penicillin-binding proteins and the quinolone- resistance-determining region of $C$. resistens DSM 45100} In addition to lipophilism and virulence, multi-drug resistance is another prominent feature of the hitherto detected clinical isolates of $C$. resistens [14]. The relevance of chromosomal genes for the multi-drug resistance profile of C. resistens DSM 45100 is apparent when considering the results of the initial antimicrobial susceptibility assays with several $\beta$-lactams, the most broadly used class of antimicrobials, and the fluoroquinolone antibiotic ciprofloxacin. All $C$. resistens isolates were characterized by high minimum inhibitory concentrations (MICs) of the selected antibiotics [14]. The resistance of $C$. resistens DSM 45100 to $\beta$-lactams might be associated with the presence of antibiotic-insensitive types of penicillin-binding proteins [76]. The chromosome of $C$. resistens DSM 45100 encodes six penicillin-binding proteins (PBPs) belonging to three protein families. PBP1A and PBP1B are bifunctional 
transglycosylases/transpeptidases of the high-molecular weight PBP 1A family, whereas the proteins PBP2A, $\mathrm{PBP} 2 \mathrm{~B}$, and $\mathrm{PBP} 2 \mathrm{C}$ act as transpeptidases and are members of the high-molecular weight PBP 2 family [67]. The Dac protein of C. resistens DSM 45100 represents a D-alanyl-D-alanine carboxypeptidase of the low-molecular weight PBP 4 family [67]. Moreover, C. resistens DSM 45100 contains two genes, $l d t 1$ (CRES_0602) and $l d t 2$ (CRES_0140), encoding putative L,D-transpeptidases. These enzymes can act in an alternative pathway for peptidoglycan cross-linking and can thus contribute to the resistance to $\beta$-lactam antibiotics that inhibit the penicillin-binding proteins, which usually catalyze the cross-linking reaction [67]. In C. jeikeium K411, the high-molecular weight penicillin-binding protein $\mathrm{PBP} 2 \mathrm{C}$ and the L,Dtranspeptidase Ldt1 were shown to be two ampicillininsensitive cross-linking enzymes involved in peptidoglycan biosynthesis [77].

Resistance to fluoroquinolones is often caused by mutations in the so-called quinolone-resistance-determining region (QRDR) of the gyrase gene gyrA [78]. The minimum inhibitory concentrations of fluoroquinolones determined in this study revealed high-level resistances of C. resistens DSM 45100 to danofloxacin $\left(32 \mu \mathrm{g} \mathrm{ml}^{-1}\right)$, ciprofloxacin, levofloxacin, sparfloxacin $\left(64 \mu \mathrm{g} \mathrm{ml}^{-1}\right)$, and norfloxacin $\left(128 \mu \mathrm{g} \mathrm{ml}^{-1}\right)$. Single amino acid substitutions in position 90 of the GyrA protein (C. resistens numbering) are generally sufficient to generate fluoroquinolone resistance in corynebacteria, but double mutations in the gyrA gene leading to changes in positions 90 and 94 of the gene product are necessary for high-level resistances [79]. The GyrA protein of C. resistens DSM 45100 contains typical amino acid residues in the deduced QRDR that are related to high-level fluoroquinolone resistance. In particluar, the amino acid sequence motif LAIYG is characterized by the Leu-90 and Gly-94 residues, which were already associated with high-level resistances to ciprofloxacin, levofloxacin, and norfloxacin in clinical isolates of Corynebacterium macginleyi $[79,80]$. Likewise, specific double mutations in the QRDR of the gyrA genes from Corynebacterium striatum and Corynebacterium amycolatum resulted in amino acid changes in positions 90 and 94 of the GyrA proteins (C. resistens numbering) and in high levels of fluoroquinolone resistance $[79,80]$. Moreover, single mutations in the gyrA gene of Escherichia coli leading to changes of the deduced QRDR sequence SAVYD to either LAVYD or SAVYG were associated with resistances to ciprofloxacin and ofloxacin [81]. It is thus very likely that specific mutations in the QRDR of the gyrA gene of C. resistens DSM 45100 are responsible for high-level resistances to fluoroquinolones. Other antibiotic resistance phenotypes of $C$. resistens DSM 45100 are apparently associated with the presence of plasmid pJA144188 that is analyzed in more detail in the following section.

\section{The modular architecture of the multi-drug resistance plasmid pJA144188}

The annotation of the complete nucleotide sequence of plasmid pJA144188 from C. resistens DSM 45100 revealed a modular genetic structure of this replicon (Figure 2). The backbone of the plasmid is apparently loaded with several mobile genetic elements and antibiotic resistance genes, including a new class 1 integron. The insertion sequences and transposons of pJA144188 form the boundaries of five distinct DNA segments, each most probably acquired by horizontal gene transfer (Figure 2). The DNA segments of pJA144188 were assigned as follows: (module I) replication region and plasmid backbone with similarity to the multi-drug resistance plasmid pTP10 from the opportunistic human pathogen C. striatum M82B; (module II) macrolide-lincosamide-streptogramin (MLS) resistance region with similarity to pNG2 from the human pathogen $C$. diphtheriae S601; (module III) tetracycline resistance region with similarity to pLR581 from Lactobacillus reuteri ATCC 55730, which encodes the ribosomal protection protein Tet(W) and is reported here for the first time to occur in corynebacteria; (module IV) chloramphenicol and aminoglycoside resistance region with similarity to the Tn45 family transposon Tn5717a from the human pathogen C. urealyticum DSM 7109; (module $\mathrm{V})$ class 1 integron that is specified by the presence of the rare aacA1:gcuG gene pair and the aadA1a gene cassette.

The small plasmid backbone of pJA144188 (module I) is characterized by the presence of the rep $W$ gene encoding the replication initiator protein RepW, whose amino acid sequence contains the characteristic signature motif GVPYGKYPR of IncW plasmids [82] and is almost identical to the RepA protein of pTP10 from C. striatum M82B [83]. Plasmid pJA144188 is thus a new member of the small IncW family of corynebacterial plasmids that probably uses the theta-type mechanism for replication [82]. The IncW family of corynebacterial plasmids includes moreover the bacteriocin-producing plasmid pKW4 from C. jeikeium K411 [25], the cryptic plasmid pCRY4 from C. glutamicum LP-6 obtained from a pig-manure deodorizing plant [84] and the low-copy-number plasmid pLEW279b from Corynebacterium sp. L2-79-05 isolated from poultry litter [85]. Characteristic 22-bp iterons, previously detected also on plasmid pTP10 [83], are present downstream of the rep $W$ coding region on pJA144188, occurring seven times. Such multiple sites of directly repeated sequences were identified in the origin regions of several plasmids. They are essential DNA-binding sites of the plasmid-specific replication initiator protein and have additional replication and copy number control properties 
[86]. As the remaining genes of pJA144188 are not related to typical plasmid replication and maintenance functions, it is most likely that the rep $W$ gene region and the replication initiator protein RepW are solely responsible for the stable inheritance of pJA144188 in C. resistens DSM 45100.

\section{DNA modules of plasmid pJA144188 containing antibiotic resistance regions}

Module II of plasmid pJA144188 includes the erm(X) gene encoding a $23 \mathrm{~S}$ rRNA adenine $N$-6-methyltransferase [87]. The $\operatorname{erm}(\mathrm{X})$ gene is preceded by IS3504 and a short leader peptide gene that might be involved in posttranscriptional regulation of erm $(\mathrm{X})$ expression by erythromycin-inducible translational attenuation [88]. An almost identical DNA region is present on plasmid pNG2 from the erythromycin-resistant human pathogen C. diphtheriae S601 [89] that was isolated during an outbreak of diphtheria in Seattle [90]. Previous antimicrobial susceptibility assays demonstrated that the $\mathrm{erm}(\mathrm{X})$ gene provides high resistance levels to clinically relevant macrolides and lincosamides, such as erythromycin, azithromycin, josamycin, midecamycin, roxithromycin, spiramycin, tylosin, clindamycin, and lincomycin, and to the streptogramin B antibiotics quinupristin and pristinamycin $\mathrm{I}_{\mathrm{A}}[83,91,92]$. This tremendous cross-resistance profile of $\operatorname{Erm}(\mathrm{X})$ can be understood when considering the common binding site of MLS antibiotics in the bacterial ribosome that is determined by the A2058 residue (E. coli numbering) in the large ribosomal subunit RNA [93].

Module IV of plasmid pJA144188 comprises the complex structure of transposon $\operatorname{Tn} 5717 c$ that is highly similar to transposon $\operatorname{Tn} 5717 a$ from the chromosome of $C$. urealyticum DSM 7109 (Figure 2). Tn5717c is thus an interlacing of the chlorampenicol resistance transposon $\operatorname{Tn} 45$, the streptomycin resistance transposon Tn5393, and the aminoglycoside resistance transposon $\operatorname{Tn} 5715$, and seems to have its seed in Tn45 detected on pXZ10145 from C. glutamicum 1014 [94] and in the chromosome of C. urealyticum DSM 7109 [24]. Transposon Tn45 is an unusual mobile genetic element in corynebacteria that consists of a transposase gene and the $c m x$ gene coding for a chlorampenicol efflux protein of the major facilitator superfamily [83]. Transposon $\operatorname{Tn} 5393$ is, on the other hand, a typical mobile genetic element of the Tn3 family and contains the strA-strB tandem pair of antibiotic resistance genes. The former gene encodes the aminoglycoside 3"-phosphotransferase APH(3")-Ib and the latter gene the aminoglycoside 6-phosphotransferase APH(6)-Id, both specifically conferring streptomycin resistance [95]. The association of the strA-strB genes with variants of transposon Tn5393 is also found in Gram-negative phytopathogenic bacteria, such as Erwinia amylovora, Pseudomonas syringae, and Xanthomonas campestris, where the Tn5393 elements occur on large conjugative plasmids [96]. The composite transposon $\operatorname{Tn} 5715$ harbors the aminoglycoside resistance gene aphA1-IAB encoding a member of the aminoglycoside 3'-phosphotransferase protein family, APH (3')-Ic [97]. The expression of the aphA1-IAB gene from the R-plasmid pTP10 in the susceptible host C. glutamicum ATCC 13032 revealed high-level resistances to kanamycin, neomycin, lividomycin, paromomycin, and ribostamycin [83] and thus the characteristic substrate profile of an APH(3')-I enzyme [98]. The aphA1-IAB gene present on PJA144188 may therefore confer resistance to a selected set of aminoglycoside antibiotics in C. resistens DSM 45100. However, a mininum inhibitory concentration of $16 \mu \mathrm{g} \mathrm{ml}^{-1}$ was detected for the aminoglycoside amikacin in the initial taxonomic description of C. resistens DSM 45100 [14]. This observation indicates that additional resistance determinants are present in C. resistens DSM 45100 and confer a broader spectrum of aminoglycoside resistances.

\section{The class 1 integron of plasmid pJA144188 and its gene cassettes encoding aminoglycoside resistance proteins} Module V of plasmid pJA144188 comprises typical genes of class 1 integrons that constitute genetic systems for gene capture and gene expression and are composed of conserved 5' and 3' segments [99,100]. The 5' conserved segment contains an integrase gene intI1, followed by the recombination site attI1, where gene cassettes are integrated by site-specific recombination after the integrase has recognized their 59-bp element. The 3' conserved segment of class 1 integrons is often specified by the presence of the qacE $\Delta 1$, sul1, and orf5 genes $[99,100]$. The sul1 gene encodes dihydropteroate synthase that can confer resistance to a broad spectrum of sulfonamides. The class 1 integron of pJA144188 is characterized by small deletions in the 5' and 3' conserved segments and by a gene cassette array that comprises three coding regions: the rare aacA1:gcuG tandem gene cassette and the aadA1a gene cassette (Figure 5A). The aminoglycoside resistance gene aadA1a encodes the aminoglycoside 3"-adenyltransferase ANT(3")-Ia with a specific substrate profile comprising only streptomycin and spectinomycin [98]. The aacA1 gene encodes the aminoglycoside 6'-acetyltransferase AAC (6')-Ia that can confer resistance to kanamycin, amikacin, dibekacin, netilmicin, sisomicin, and tobramycin [98]. It is thus likely that the aacA1 gene of pJA144188 mediates the observed resistance of $C$. resistens DSM 45100 to amikacin [14].

It is remarkable that the aacA1 resistance gene and the gcuG gene of unknown function represent a gene pair that is present in a single gene cassette and thus not separated by a 59-bp element [100]. The fused aacA1:gcuG gene cassette is rare in class 1 integrons and it has been observed in corynebacteria for the first time in the present study. 


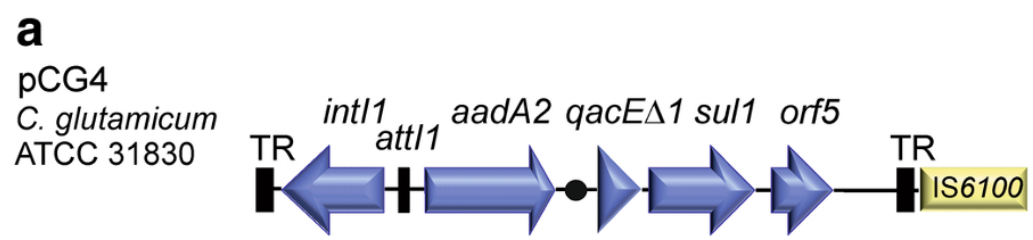

pTET3

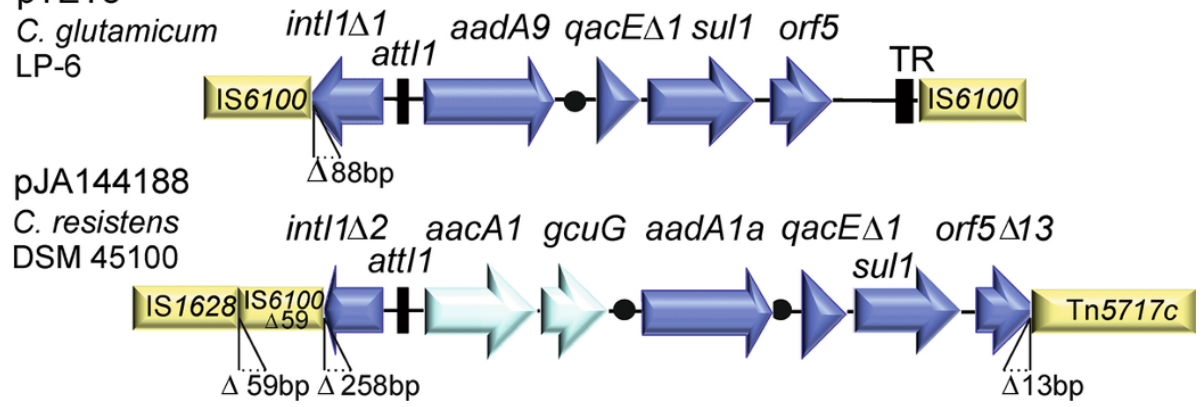

b
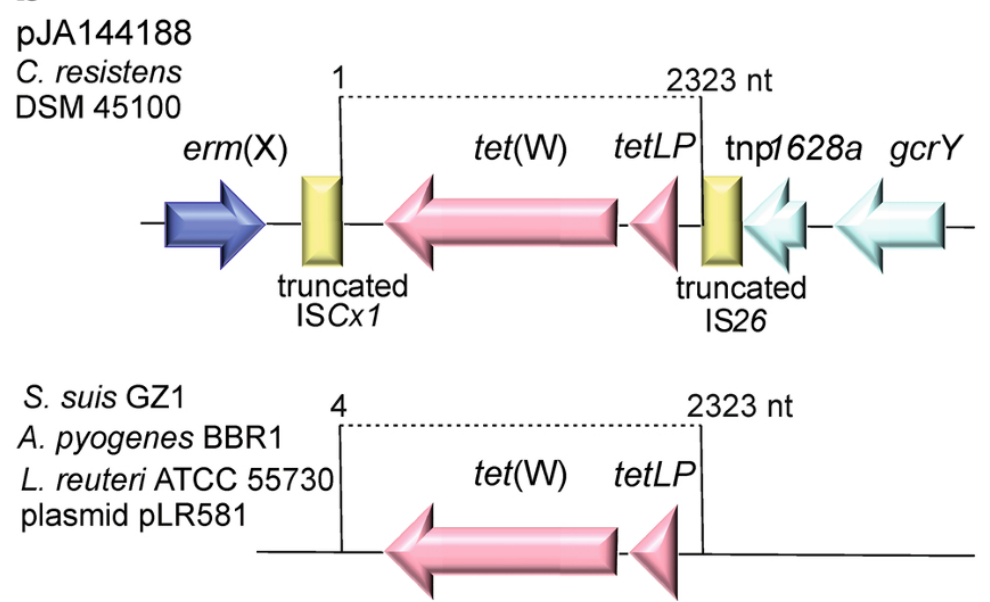

Figure 5 Prominent genetic features of plasmid pJA144188 from C. resistens DSM 45100 (A), Genetic structure of corynebacterial class 1 integrons. A comparison of the class 1 integron from pJA144188 with those present on plasmids PTET3 and pCG4 from C. glutamicum strains is shown. The filled circles indicate the position of 59-bp elements downstream of gene cassettes. The aacA1 and gcuG genes represent a gene pair that is not separated by a 59-bp element. The cassette integration site att/1 and the terminal repeat sequences (TR) are shown as black boxes. Deletions characterizing the class 1 integrons on pJA144188 and pTET3 are indicated. (B), Detailed view of the tetracycline resistance gene region of pJA144188. The tet $(\mathrm{W})$ gene region is presented including the predicted leader peptide gene tetLP. The truncated insertion sequences ISCXI and IS26 flanking the tet $(\mathrm{W})$ gene region are shown as yellow boxes. These remnants of insertion sequences form the boundaries of a 2,323 bp DNA sequence that is also present in Streptococcus suis, Arcanobacterium pyogenes, and Lactobacillus reuteri, with the exception of three terminal nucleotides at the 5' end.

Other class 1 integrons containing the aacA1:gcuG gene pair were detected, for instance, on plasmid pKGB525 from Klebsiella pneumoniae [101], on pCMXR1 from $E$. coli HKYM68 [102], and on the R factor NR79 from $E$. coli W677 [103]. Commonly, integrons are features of Gram-negative bacteria and only few integrons have been reported from Gram-positive bacteria, including two class 1 integrons from corynebacteria (Figure 5A). The first corynebacterial integron was detected on plasmid pCG4 from C. glutamicum ATCC 31830 [104] and the second element on plasmid pTET3 from C. glutamicum LP-6 [105]. The integron of pCG4 contains the aadA2 gene cassette, whereas the aadA9 gene cassette was detected on pTET3. Both genes confer streptomycin-spectinomycin resistance and encode aminoglycoside 3"-adenyltransferases of the ANT(3")-I protein family [98]. Accordingly, plasmid pJA144188 carries a new class 1 integron with two gene cassettes probably contributing to the extended spectrum of aminoglycoside resistances in C. resistens DSM 45100.

The tetracycline-minocycline resistance region of plasmid pJA144188

Module III of plasmid pJA144188 contains the tet(W) gene, which is preceded by the putative leader peptide 
gene tetLP (Figure 2). The deduced Tet(W) protein revealed $99 \%$ identity, with only three substitutions in the amino acid sequence, to Tet(W) encoded on plasmid pLR581 from Lactobacillus reuteri ATCC 55730, a commercially available probiotic strain [106]. Tet(W) represents a ribosomal protection protein (RPP) that can promote high-level resistance to tetracyclines in Gram-positive and Gram-negative bacteria [107]. RPPs are supposed to originate from bacterial elongation factors and mediate tetracycline resistance by a complex molecular mechanism: They dislodge tetracycline from the ribosome, which is occupied by the antibiotic, such that an aminoacyl-tRNA can bind to the A site of the ribosome and protein biosynthesis can continue. RPPs can thus overcome the antimicrobial effect of typical tetracyclines, which bind to the ribosome and inhibit the elongation phase of protein biosynthesis [107]. The tetracycline resistance region of pJA144188 covers a 2,323-bp DNA sequence that is almost identical to tet(W) gene regions in Streptococcus suis GZ1 [108], Arcanobacterium pyogenes BBR1 [109], and to tet(W) on plasmid pLR581 from L. reuteri ATCC 55730 [106] (Figure 5B). This DNA segment obviously represents a conserved tet(W) core region in these Gram-positive species, whereas the flanking sequences of tet(W) genes are highly diverse in these species and in other bacteria [110]. The boundaries of the tetracycline resistance region on pJA144188 are clearly defined by the presence of two remnants of insertion sequences (Figure 5B). The truncated ISC $x 1$ element is known from the $C$. diphtheriae 6601 plasmid pNG2 and located downstream of the tet(W) gene, whereas a 47-bp stretch of DNA with identity to the 5' end of IS26 is present upstream of the tet $L P$ gene.

To elucidate the capability of the $t e t(\mathrm{~W})$ gene product to mediate resistance to tetracyclines, including minocycline, the tet $(\mathrm{W})$ gene region was amplified by PCR and the resulting DNA fragment was cloned in E. coli DH5 $\alpha \mathrm{MCR}$ into the shuttle vector pEC-K18mob2. The recombinant plasmid, designated pKM22, was subsequently transferred into the antibiotic-susceptible host strain C. glutamicum ATCC 13032, resulting in C. glutamicum KM22. The role of the cloned tet $(\mathrm{W})$ gene in tetracycline resistance was examined in C. glutamicum KM22 by measuring the MICs of tetracycline and oxytetracycline (first generation tetracyclines), doxycycline and minocycline (second generation tetracyclines), and the atypical tetracycline analog anhydrotetracycline. Additional antimicrobial susceptibility assays served as controls and were performed with C. resistens DSM 45100 and C. glutamicum ATCC 13032 carrying the empty cloning vector pEC-K18mob2. These assays revealed that C. glutamicum KM22 gained a remarkable resistance to first and second generation tetracyclines in comparison with the control strain C. glutamicum ATCC 13032, displaying MICs from $8 \mu \mathrm{g} \mathrm{ml}^{-1}$ to 32 $\mu \mathrm{g} \mathrm{ml}^{-1}$ (Table 3). Slightly higher MICs were measured in C. resistens DSM 45100 (Table 3). On the other hand, the tested corynebacterial strains revealed the same MIC in the assay with anhydrotetracycline, indicating that the ribosomal protection protein Tet(W) may not confer resistance to this atypical tetracycline analog. This result of the antimicrobial susceptibility assay is obvious as the primary target of anhydrotetracycline is not the bacterial ribosome and the process of translation. The antimicrobial activity of anhydrotetracycline is exerted instead by disrupting bacterial membranes $[111,112]$. In conclusion, the tet(W) gene of pJA144188 is a very likely candidate to confer minocycline resistance in C. resistens DSM 45100 and might be responsible for the failure of minocycline therapy in patients with $C$. resistens bacteremia.

To assess the effect of a subinhibitory concentration of tetracycline $\left(2 \mu \mathrm{g} \mathrm{ml}^{-1}\right)$ on the transcription of tet $(\mathrm{W})$ in C. resistens DSM 45100, the transcript levels of the tet (W) mRNA were determined in induced and non-induced cultures by real-time reverse transcription (RT)-PCR. For this purpose, total RNA samples were purified from C. resistens DSM 45100 cultures exposed to $2 \mu \mathrm{g} \mathrm{ml}^{-1}$ tetracycline for $24 \mathrm{~h}$ (induced condition) and control cultures grown in the absence of tetracycline (non-induced condition). Indeed, the transcript level of tet(W) was 52-fold higher in the C. resistens DSM 45100 culture that has been exposed to tetracycline for $24 \mathrm{~h}$, when compared to the control culture. This data indicated that the expression of the tet $(\mathrm{W})$ gene on pJA144188 is regulated at the level of transcription and inducible by tetracycline in C. resistens DSM 45100. The respective molecular mechanism is currently unknown, and the role of the putative leader peptide gene in this process, if any, remains to be elucidated. The ribosomal protection gene tet $(\mathrm{M})$ from Staphylococcus aureus MRSA101 is also inducible by tetracycline at the level of transcription [113]. Expression studies revealed a greatly increased amount of tet(M)-specific mRNA when the $S$. aureus cells were first treated with a subinhibitory

Table 3 Minimum inhibitory concentrations $\left[\mu \mathrm{g} \mathrm{ml}^{-1}\right.$ ] of tetracyclines against C.resistens and C. glutamicum

\begin{tabular}{llllll}
\hline Strain & Tetracycline & Oxytetracycline & Doxycycline & Minocycline & Anhydrotetracycline \\
\hline CRES DSM 45100 & 64 & 32 & 16 & 16 & 8 \\
CGLU ATCC 13032 & 0.5 & 1 & 1 & 0.5 & 8 \\
CGLU KM22 & 32 & 32 & 8 & 16 & 8 \\
\hline
\end{tabular}

${ }^{a}$ C. glutamicum ATCC 13032 carrying the empty cloning vector $\mathrm{pEC}-\mathrm{K} 18 \mathrm{mob} 2$ 
amount of tetracycline. The tet $(\mathrm{M})$ gene was previously also observed by Southern techniques in C. striatum strains from clinical specimens [114].

\section{Conclusions}

In this study, we describe the complete genome sequence and annotation of the multi-drug resistant clinical isolate C. resistens DSM 45100. The sequence analysis revealed comprehensive insights into the metabolic features, virulence functions, and mechanisms for antibiotic resistance of this human pathogen. The integration of these data provides for the first time a detailed view on the deduced lifestyle of $C$. resistens (Figure 6). The strict lipophilic lifestyle of this species is obviously caused by the absence of genes for fatty acid synthesis, sugar uptake, and anaplerotic functions. Therefore, gene loss is the dominant evolutionary mechanism in shaping the metabolic features of C. resistens, which are most probably related to the natural habitat. C. resistens might colonize of the inguinal or perineal regions of the human body, as these sites of the skin provide elevated amounts of fatty acid substrates for growth by natural secretions that contribute to the formation of hydrolipid films. Moreover, the utilization of L-histidine as a nitrogen or carbon source by enzymes encoded by the hut genes suggests that $C$. resistens lives in close proximity to the human genital tract, since the presence of the hut pathway is predominantly associated with corynebacteria causing urogenital tract infections. The strict lipophilic lifestyle of $C$. resistens is also linked with enzymatic functions of several predicted virulence factors, which probably ensure the availability of external fatty acids for growth by causing damage to membranes of host cells. Accordingly, the predicted repertoire of candidate virulence factors might explain the low pathogenic potential of $C$. resistens.

The extensive multi-drug resistance of $C$. resistens DSM 45100 is apparently caused by distinct features of chromosomal genes and the presence of plasmid pJA144188. The sequence annotation of pJA144188 provided detailed insights into the gene composition and the modular genetic organization of this plasmid, thereby revealing that horizontal gene transfer represents a key factor in the development of multi-drug resistance in C. resistens. A similar set of antibiotic resistance genes is present in other multi-drug resistant corynebacteria, such as C. striatum,

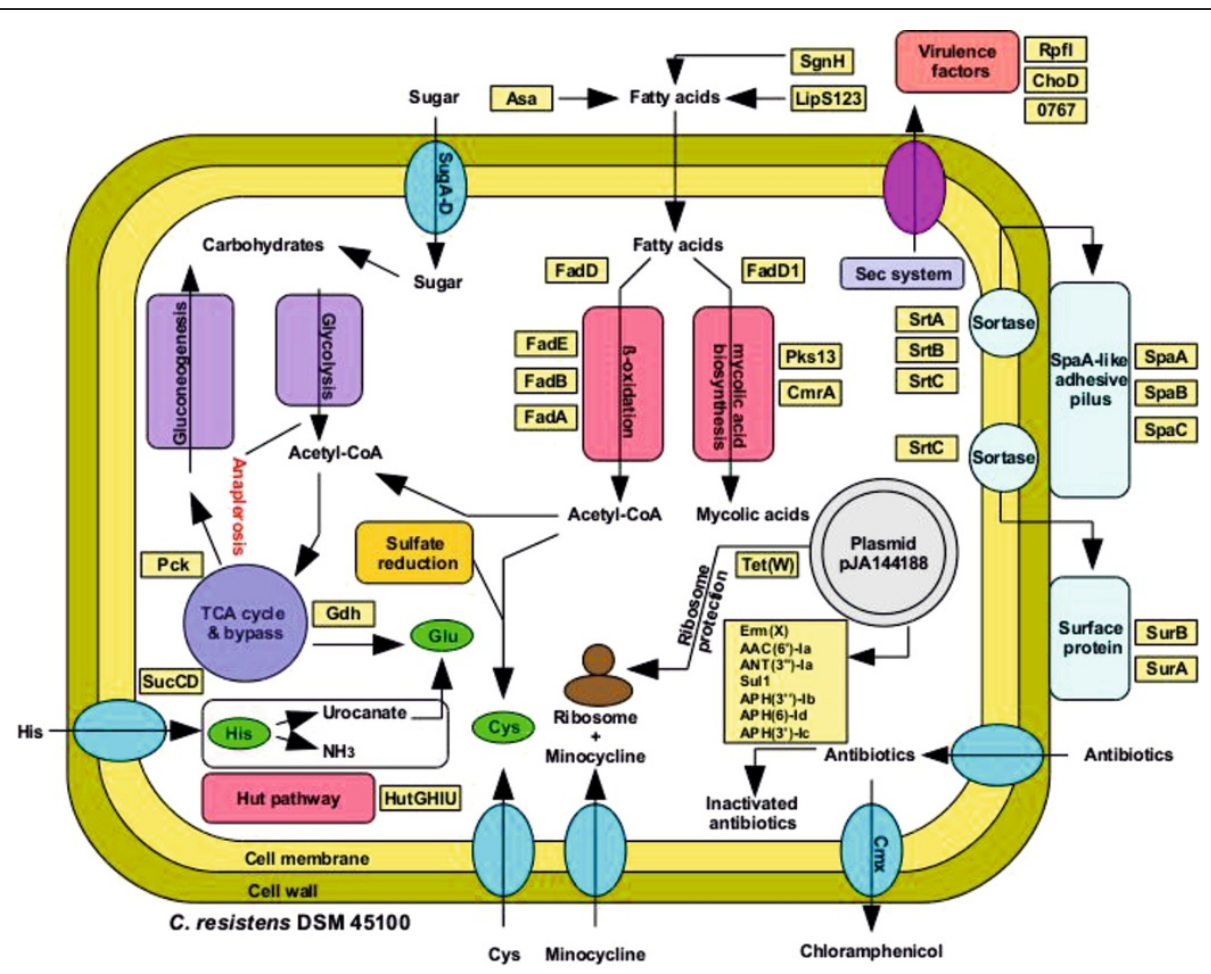

Figure 6 Overview of prominent metabolic and medically relevant features of C. resistens DSM 45100 deduced from the complete genome sequence. Metabolic features associated with carbohydrate metabolism, histidine utilization, sulfate reduction, fatty acid metabolism, mycolic acid biosynthesis, and pilus formation are shown. Relevant proteins assigned to these processes are labeled by yellow boxes; relevant transport systems are shown as blue circles. The predicted virulence factors are probably secreted by the machinery of the general secretory pathway (Sec system). The role of the predicted virulence factors in ensuring the availability of exogenous fatty acids for growth of C. resistens is remarkable. The presence of pJA144188 in C. resistens DSM 45100 is indicated and the encoded antibiotic resistance proteins are listed. The role of the Tet(W) protein in ribosomal protection of C. resistens DSM 45100 is highlighted, as it is most likely responsible for the clinically relevant resistance to minocycline. 
C. urealyticum, and C. jeikeium. This collection includes the $\operatorname{erm}(\mathrm{X})$ and $\operatorname{cmx}$ genes, as well as aphA1-IAB and the str $A$-str $B$ tandem gene pair $[24,25,115]$. The tet $(\mathrm{W})$ gene of pJA144188 encodes a ribosomal protection protein that confers resistance to first and second generation tetracyclines, including the clinically relevant tetracycline derivative minocycline. The presence of the tet $(\mathrm{W})$ gene on pJA144188 has tremendous impact on the treatment of human infections associated with C. resistens, as the crossresistance profile of the Tet(W) protein can contribute to the failure of minocycline therapies in (immunocompromised) patients.

\section{Methods}

\section{Bacterial strains and growth conditions}

C. resistens DSM 45100 (GTC 2026, CCUG 50093) was obtained as a lyophilized culture from DSMZ (Braunschweig, Germany) and routinely grown on solid BYT medium at $37^{\circ} \mathrm{C}$ [116]. This clinical isolate was originally recovered from a positive blood culture taken from a patient with acute myelocytic leukemia and initially named SICGH 158 [14]. E. coli DH5 $\alpha$ MCR was used for standard cloning procedures and cultured on Luria-Bertani medium at $37^{\circ} \mathrm{C}$ [117]. The wild-type strain C. glutamicum ATCC 13032 (American Type Culture Collection, Manassas, VA) was routinely grown at $30^{\circ} \mathrm{C}$ in CGXII minimal medium containing $30 \mu \mathrm{g} \mathrm{l^{-1 }}$ protocatechuic acid and $420 \mu \mathrm{g} \mathrm{l}^{-1}$ thiamine [118]. Kanamycin was used for the selection of plasmids in E. coli $\left(50 \mu \mathrm{g} \mathrm{ml}^{-1}\right)$ and C. glutamicum $\left(25 \mu \mathrm{g} \mathrm{ml}^{-1}\right)$. The growth of shake-flask cultures was monitored by measuring the optical density at $600 \mathrm{~nm}$ with an Eppendorf BioPhotometer.

\section{Genome sequencing of $C$. resistens DSM 45100}

Genomic DNA of C. resistens DSM 45100 was purified by an alkaline lysis procedure [119] from 20-ml aliquots of an overnight culture grown in liquid BYT medium supplemented with $1.25 \%(\mathrm{w} / \mathrm{v})$ glycine. The original lysis protocol was modified as follows: (i) The C. resistens cells were incubated in a $30 \mathrm{mg} \mathrm{ml}^{-1}$ lysozyme solution at $37^{\circ} \mathrm{C}$ for $1 \mathrm{~h}$. (ii) The harvested cells were lysed in $0.7 \mathrm{ml} 10 \%$ (w/v) SDS solution at $37^{\circ} \mathrm{C}$ for $15 \mathrm{~min}$. A total of $5 \mu \mathrm{g}$ of purified genomic DNA from C. resistens DSM 45100 was used for constructing a single-stranded template DNA library. The preparation and sequencing of the DNA library were performed according to standard protocols from Roche Applied Science. The Genome Sequencer FLX System and Titanium chemistry (Roche Applied Science) were applied for sequencing of the genomic DNA. The sequence reads were assembled with the GS Assembler Software (version 2.3).

The remaining gaps in the genome sequence of C. resistens DSM 45100 were closed by PCR with Phusion hot start high-fidelity DNA polymerase
(Finnzymes) and genomic template DNA. All primers used in this study were synthesized by Metabion. The PCR assays were carried out with a TProfessional PCR thermocylcer (Biometra) according to standard protocols (Finnzymes). The amplified DNA fragments linking the individual contigs were sequenced by IIT Biotech. Chromosomal DNA sequences and plasmid sequences were uploaded separately into the Consed program [16] to generate the complete genome sequence of C. resistens DSM 45100.

\section{Annotation and bioinformatic analysis of the genome sequence}

The assembled sequences of C. resistens DSM 45100 were uploaded into the bacterial genome annotation system GenDB [17]. The automatic annotation of the complete genome sequence was performed as described previously [25], followed by manual curation of the data. The genome plot of C. resistens DSM 45100 was generated with the web tool DNAPlotter [120]. The origin of chromosomal replication of $C$. resistens was predicted with the web version of the Ori-Finder tool [20]. Clustered regularly interspaced short palindromic repeats (CRISPRs) were detected with the CRISPRFinder tool [30]. Analyses of the predicted gene content and the metabolic properties of $C$. resistens were accomplished by the software tools EDGAR [22] and CARMEN [121], using their default parameters. The synteny between the chromosome of C. resistens DSM 45100 and that of C. jeikeium K411 was calculated by the EDGAR software [22].

The annotated sequence of the C. resistens DSM 45100 chromosome has been deposited in the GenBank database with accession number CP002857 and is available from the RefSeq database with accession number NC_015673. The sequence of plasmid pJA144188 is available from GenBank with accession number FN825254 and from RefSeq with accession number NC_014167.

\section{Antimicrobial susceptibility assays with tetracyclines and fluoroquinolones}

The antimicrobial susceptibilities of C. resistens DSM 45100, C. glutamicum ATCC 13032 and C. glutamicum KM22 were determined in vitro by a macrobroth dilution method according to the guidelines of the Clinical and Laboratory Standards Institute [122]. The antibiotics tetracycline, oxytetracycline, doxycycline, minocycline, and anhydrotetracycline as well as the fluoroquinolones ciprofloxacin, danofloxacin, levofloxacin, norfloxacin, and sparfloxacin were purchased from Sigma-Aldrich. All antibiotics were tested in vitro in the range of 0.1 to $256 \mu \mathrm{g} \mathrm{ml}^{-1}$. The corynebacterial cells were grown in Mueller-Hinton broth (Merck) supplemented with 1\% (v/v) Tween 80 . The minimum inhibitory concentration (MIC) was taken as the lowest concentration of the 
antibiotic to completely inhibit the visible growth of the bacteria after incubation for $24 \mathrm{~h}$ at $37^{\circ} \mathrm{C}$ [122].

\section{Cloning of the tet $(\mathrm{W})$ gene from C. resistens DSM 45100} The preparation of plasmid DNA from E. coli DHaMCR cells was performed by an alkaline lysis technique using the QIAprep Spin Miniprep Kit (Qiagen). The protocol was modified for C. glutamicum cells by using $20 \mathrm{mg} \mathrm{ml}^{-1}$ lysozyme in resuspension buffer $\mathrm{P} 1$ and by incubating the assay at $37^{\circ} \mathrm{C}$ for $3 \mathrm{~h}$. DNA restriction, DNA analysis by agarose gel electrophoresis, and DNA ligation were performed according to standard procedures [117]. The transformation of plasmid DNA was carried out by electroporation using electrocompetent E. coli and C. glutamicum cells $[123,124]$. The tet $(\mathrm{W})$ gene was amplified by PCR with the primer pair tet(W)fwd (GATCTAG-GA TCCGTGCGGGGAAGAAAAAT) and tet(W)rev (GATCTATCTAGACGCAATAGCCAG-CAATGA). The amplified tet $(\mathrm{W})$ gene was cloned in E. coli $\mathrm{DH} \alpha \mathrm{MCR}$ into the shuttle vector pEC-K18mob2 [124], resulting in plasmid pKM22. DNA of pKM22 was isolated from E. coli and subsequently transferred into C. glutamicum ATCC 13032, leading to strain C. glutamicum KM22.

\section{RNA techniques and measurement of tet(W) transcript levels}

The isolation and purification of total RNA from C. resistens DSM 45100 cultures was carried out as described previously [125]. The strain was grown in BYT medium without tetracycline (non-induced) and in BYT medium supplemented with $2 \mu \mathrm{g} \mathrm{ml}^{-1}$ tetracycline (induced). The transcript levels of the tet $(\mathrm{W})$ gene were measured by realtime reverse transcriptase PCR (RT-PCR) with the LightCycler instrument (Roche Applied Science), using the SensiMix One-Step Kit (Quantace) and the primer pair tet (W)LC1 (TTCGATGGTGGCACAGTA) and tet(W)LC2 (TTGTTCGGCTGGAACGTA). The differences in tet(W) transcript levels between induced and non-induced cultures of $C$. resistens DSM 45100 were determined by comparing the crossing points of two biological samples, each measured with two technical replicates. Crossing points were calculated by the LightCycler software (Roche Applied Science). The measured crossing point (CP) is the cycle at which PCR amplification begins its exponential phase and is considered the point that is most reliably proportional to the initial RNA concentration. The relative change in tet $(\mathrm{W})$ transcript levels was determined as $2^{-\Delta C P}$, with $\triangle \mathrm{CP}$ being equal to the difference of the measured crossing points for the test (induced) and the control (noninduced) condition. The quality of the measurements was ensured by melting curve analysis with the LightCycler software (Roche Applied Science).

\section{Additional material}

Additional file 1: Annotation of pathways involved in central carbohydrate metabolism of $C$. resistens DSM 45100. The PDF contains a metabolic reconstruction based on manually curated pathway maps related to the central carbohydrate metabolism.

Additional file 2: Annotation of pathways involved in amino acid metabolism of $C$. resistens DSM 45100. The PDF contains a metabolic reconstruction based on manually curated pathway maps related to the uptake and metabolism of amino acids.

\section{Acknowledgements}

ET and JES acknowledge the receipt of scholarships that are embedded into the Cluster Industrial Biotechnology and financed by Bielefeld University and the Ministry of Innovation, Science, Research and Technology of North Rhine-Westphalia. JB thanks the genomic transfer program (grant 0315599B) of the BMBF. The valuable contribution of the CeBiTec sequencing team (A. Albersmeier, R. Szczepanowski) to this genome project is greatly acknowledged. The authors thank the sequencing team from IIT GmbH (Bielefeld) for the help during the gap closure process and F. Soriano from the Fundación Jiménez Díaz (Madrid) for valuable comments on the physiological role of the hut gene cluster in corynebacteria. We acknowledge support of the publication fee by Deutsche

Forschungsgemeinschaft and the Open Access Publication Funds of Bielefeld University.

\section{Author details}

${ }^{1}$ Institut für Genomforschung und Systembiologie, Centrum für Biotechnologie, Universität Bielefeld, Universitätsstraße 27, D-33615 Bielefeld, Germany. ${ }^{2}$ Bioinformatics Resource Facility, Centrum für Biotechnologie, Universität Bielefeld, Universitätsstraße 27, D-33615 Bielefeld, Germany. ${ }^{3}$ CLIB Graduate Cluster Industrial Biotechnology, Centrum für Biotechnologie, Universität Bielefeld, Universitätsstraße 27, D-33615 Bielefeld, Germany.

\section{Authors' contributions}

JAS sequenced and annotated the genome of $C$. resistens and prepared the manuscript. IM supported the gap closure process and the annotation of the chromosome. KM participated in annotating plasmid pJA144188 and carried out the functional analysis of tet( $\mathrm{W})$. SW contributed to the manual annotation of the genome sequence and the quinolone-resistancedetermining region. JB implemented the EDGAR project for cluster 3 corynebacteria. SJ provided support for the GenDB project. JES prepared the GenBank file and provided bioinformatic support. ET and AT participated in data evaluation. All authors read and approved the final version of the manuscript.

Received: 30 September 2011 Accepted: 23 April 2012 Published: 23 April 2012

\section{References}

1. Ventura M, Canchaya C, Tauch A, Chandra G, Fitzgerald GF, Chater KF, van Sinderen D: Genomics of Actinobacteria: tracing the evolutionary history of an ancient phylum. Microbiol Mol Biol Rev 2007, 71:495-548.

2. Mattos-Guaraldi AL, Moreira LO, Damasco PV, Hirata R Jr: Diphtheria remains a threat to health in the developing world-an overview. Mem Inst Oswaldo Cruz 2003, 98:987-993.

3. Funke G, von Graevenitz A, Clarridge JE, Bernard KA: Clinical microbiology of coryneform bacteria. Clin Microbiol Rev 1997, 10:125-159.

4. Bernard KA, Munro C, Wiebe D, Ongsansoy E: Characteristics of rare or recently described Corynebacterium species recovered from human clinical material in Canada. J Clin Microbiol 2002, 40:4375-4381.

5. von Greavenitz A, Bernard KA: The Genus Corynebacterium-Medical. The Prokaryotes. 3 edition. New York: Springer; 2006, 819-842.

6. Khamis A, Raoult D, La Scola B: rpoB gene sequencing for identification of Corynebacterium species. J Clin Microbiol 2004, 42:3925-3931. 
7. Soriano F, Tauch A: Microbiological and clinical features of Corynebacterium urealyticum: urinary tract stones and genomics as the Rosetta Stone. Clin Microbiol Infect 2008, 14:632-643.

8. Belmares J, Detterline S, Pak JB, Parada JP: Corynebacterium endocarditis species-specific risk factors and outcomes. BMC Infect Dis 2007, 7:4.

9. van der Lelie $H$, Leverstein-Van Hall M, Mertens M, van Zaanen HC, van Oers RH, Thomas BL, von dem Borne AE, Kuijper EJ: Corynebacterium CDC group JK (Corynebacterium jeikeium) sepsis in haematological patients: a report of three cases and a systematic literature review. Scand I Infect Dis 1995, 27:581-584.

10. De Briel D, Langs JC, Rougeron G, Chabot P, Le Faou A: Multiresistant corynebacteria in bacteriuria: a comparative study of the role of Corynebacterium group D2 and Corynebacterium jeikeium. J Hosp Infect 1991, 17:35-43.

11. Garcia-Rodriguez JA, Garcia Sanchez JE, Munoz Bellido JL, Nebreda Mayoral T, Garcia Sanchez E, Garcia Garcia I: In vitr activity of 79 antimicrobial agents against Corynebacterium group D2. Antimicrob Agents Chemother 1991, 35:2140-2143.

12. Nieto E, Vindel A, Valero-Guillen PL, Saez-Nieto JA, Soriano F: Biochemical, antimicrobial susceptibility and genotyping studies on Corynebacterium urealyticum isolates from diverse sources. J Med Microbiol 2000, 49:759-763.

13. Garcia-Bravo M, Aguado JM, Morales JM, Noriega AR: Influence of external factors in resistance of Corynebacterium urealyticum to antimicrobial agents. Antimicrob Agents Chemother 1996, 40:497-499.

14. Otsuka Y, Kawamura Y, Koyama T, lihara H, Ohkusu K, Ezaki T: Corynebacterium resistens sp. nov., a new multidrug-resistant coryneform bacterium isolated from human infections. J Clin Microbiol 2005, 43:3713-3717.

15. Thaker M, Spanogiannopoulos P, Wright GD: The tetracycline resistome. Cell Mol Life Sci 2009, 67:419-431.

16. Gordon D, Abajian C, Green P: Consed: a graphical tool for sequence finishing. Genome Res 1998, 8:195-202.

17. Meyer F, Goesmann A, McHardy AC, Bartels D, Bekel T, Clausen J, Kalinowski J, Linke B, Rupp O, Giegerich R, Pühler A: GenDB-an open source genome annotation system for prokaryote genomes. Nucleic Acids Res 2003, 31:2187-2195.

18. Lagesen $\mathrm{K}$, Hallin $\mathrm{P}$, Rodland $\mathrm{E}$, Staerfeldt $\mathrm{H}$, Rognes $\mathrm{T}$, Ussery D: RNAmmer: consistent and rapid annotation of ribosomal RNA genes. Nucleic Acids Res 2007, 35:3100-3108.

19. Lowe TM, Eddy SR: tRNAscan-SE: a program for improved detection of transfer RNA genes in genomic sequence. Nucleic Acids Res 1997, 25:955-964.

20. Gao F, Zhang CT: Ori-Finder: a web-based system for finding oriCs in unannotated bacterial genomes. BMC Bioinformatics 2008, 9:79.

21. Hendrickson $\mathrm{H}$, Lawrence JG: Selection for chromosome architecture in bacteria. J Mol Evol 2006, 62:615-629.

22. Blom J, Albaum SP, Doppmeier D, Pühler A, Vorhölter FJ, Zakrzewski M, Goesmann A: EDGAR: a software framework for the comparative analysis of prokaryotic genomes. BMC Bioinformatics 2009, 10:154.

23. Nakamura $Y$, Nishio $Y$, Ikeo $K$, Gojobori T: The genome stability in Corynebacterium species due to lack of the recombinational repair system. Gene 2003, 317:149-155.

24. Tauch A, Trost E, Tilker A, Ludewig U, Schneiker S, Goesmann A, Arnold W, Bekel T, Brinkrolf K, Brune I, et al: The lifestyle of Corynebacterium urealyticum derived from its complete genome sequence established by pyrosequencing. J Biotechnol 2008, 136:11-21.

25. Tauch A, Kaiser O, Hain T, Goesmann A, Weisshaar B, Albersmeier A, Bekel T, Bischoff N, Brune I, Chakraborty T, et al: Complete genome sequence and analysis of the multiresistant nosocomial pathogen Corynebacterium jeikeium K411, a lipid-requiring bacterium of the human skin flora. $J$ Bacteriol 2005, 187:4671-4682.

26. Tauch A, Schneider J, Szczepanowski R, Tilker A, Viehoever P, Gartemann KH, Arnold W, Blom J, Brinkrolf K, Brune I, et al: Ultrafast pyrosequencing of Corynebacterium kroppenstedtii DSM44385 revealed insights into the physiology of a lipophilic corynebacterium that lacks mycolic acids. J Biotechnol 2008, 136:22-30.

27. Mackiewicz P, Mackiewicz D, Kowalczuk M, Cebrat S: Flip-flop around the origin and terminus of replication in prokaryotic genomes. Genome Biol 2001, 2:INTERACTIONS1004
28. Rocha EP, Danchin A: Essentiality, not expressiveness, drives gene-strand bias in bacteria. Nat Genet 2003, 34:377-378

29. Suzuki N, Okai N, Nonaka H, Tsuge Y, Inui M, Yukawa H: High-throughput transposon mutagenesis of Corynebacterium glutamicum and construction of a single-gene disruptant mutant library. Appl Environ Microbiol 2006, 72:3750-3755.

30. Grissa I, Vergnaud G, Pourcel C: CRISPRFinder: a web tool to identify clustered regularly interspaced short palindromic repeats. Nucleic Acids Res 2007, 35:W52-57.

31. Ishikawa J, Yamashita A, Mikami Y, Hoshino Y, Kurita H, Hotta K, Shiba T, Hattori M: The complete genomic sequence of Nocardia farcinica IFM 10152. Proc Natl Acad Sci USA 2004, 101:14925-14930.

32. Barrangou R, Fremaux C, Deveau H, Richards M, Boyaval P, Moineau S, Romero DA, Horvath P: CRISPR provides acquired resistance against viruses in prokaryotes. Science 2007, 315:1709-1712.

33. Parche S, Burkovski A, Sprenger GA, Weil B, Krämer R, Titgemeyer F: Corynebacterium glutamicum: a dissection of the PTS. $J$ Mol Microbiol Biotechnol 2001, 3:423-428.

34. Brinkrolf K, Plöger S, Solle S, Brune I, Nentwich SS, Hüser AT, Kalinowski J, Pühler A, Tauch A: The Lacl/GalR family transcriptional regulator UriR negatively controls uridine utilization of Corynebacterium glutamicum by binding to catabolite-responsive element (cre)-like sequences. Microbiology 2008, 154:1068-1081.

35. Schweizer E, Hofmann J: Microbial type I fatty acid synthases (FAS): major players in a network of cellular FAS systems. Microbiol Mol Biol Rev 2004, 68:501-517.

36. Gavalda S, Leger M, van der Rest B, Stella A, Bardou F, Montrozier H, Chalut C, Burlet-Schiltz O, Marrakchi H, Daffe M, Quemard A: The Pks13/ FadD32 crosstalk for the biosynthesis of mycolic acids in Mycobacterium tuberculosis. J Biol Chem 2009, 284:19255-19264.

37. Black PN, DiRusso CC: Transmembrane movement of exogenous longchain fatty acids: proteins, enzymes, and vectorial esterification. Microbiol Mol Biol Rev 2003, 67:454-472.

38. Pech-Canul A, Nogales J, Miranda-Molina A, Alvarez L, Geiger O, Soto MJ, Lopez-Lara IM: FadD is required for utilization of endogenous fatty acids released from membrane lipids. J Bacteriol 2011, 193:6295-6304.

39. Hiltunen JK, Qin Y: Beta-oxidation - strategies for the metabolism of a wide variety of acyl-CoA esters. Biochim Biophys Acta 2000, 1484:117-128.

40. Munoz-Elias EJ, Upton AM, Cherian J, McKinney JD: Role of the methylcitrate cycle in Mycobacterium tuberculosis metabolism, intracellular growth, and virulence. Mol Microbiol 2006, 60:1109-1122

41. Jolkver E, Emer D, Ballan S, Krämer R, Eikmanns BJ, Marin K: Identification and characterization of a bacterial transport system for the uptake of pyruvate, propionate, and acetate in Corynebacterium glutamicum. J Bacteriol 2009, 191:940-948.

42. Portevin D, De Sousa-D'Auria C, Houssin C, Grimaldi C, Chami M, Daffe M, Guilhot C: A polyketide synthase catalyzes the last condensation step of mycolic acid biosynthesis in mycobacteria and related organisms. Proc Natl Acad Sci USA 2004, 101:314-319.

43. Lea-Smith DJ, Pyke JS, Tull D, McConville MJ, Coppel RL, Crellin PK: The reductase that catalyzes mycolic motif synthesis is required for efficient attachment of mycolic acids to arabinogalactan. J Biol Chem 2007, 282:11000-11008.

44. Meniche X, Labarre C, de Sousa-d'Auria C, Huc E, Laval F, Tropis M, Bayan N, Portevin D, Guilhot C, Daffe M, Houssin C: Identification of a stressinduced factor of Corynebacterineae that is involved in the regulation of the outer membrane lipid composition. J Bacteriol 2009, 191:7323-7332.

45. Bayan N, Houssin C, Chami M, Leblon G: Mycomembrane and S-layer: two important structures of Corynebacterium glutamicum cell envelope with promising biotechnology applications. J Biotechnol 2003, 104:55-67.

46. Barzantny H, Brune I, Tauch A: Molecular basis of human body odour formation: insights deduced from corynebacterial genome sequences. Int J Cosmet Sci 2011, 34:2-11.

47. Zhang XX, Rainey PB: Genetic analysis of the histidine utilization (hut) genes in Pseudomonas fluorescens SBW25. Genetics 2007, 176:2165-2176.

48. Devriese LA, Riegel P, Hommez J, Vaneechoutte M, de Baere T, Haesebrouck F: Identification of Corynebacterium glucuronolyticum strains from the urogenital tract of humans and pigs. J Clin Microbiol 2000, 38:4657-4659.

49. Feurer C, Clermont D, Bimet F, Candrea A, Jackson M, Glaser P, Bizet C, Dauga C: Taxonomic characterization of nine strains isolated from 
clinical and environmental specimens, and proposal of Corynebacterium tuberculostearicum sp. nov. Int I Syst Evol Microbiol 2004, 54:1055-1061.

50. Vedel G, Toussaint G, Riegel P, Fouilladieu JL, Billoet A, Poyart C: Corynebacterium pseudogenitalium urinary tract infection. Emerg Infect Dis 2006, 12:355-356.

51. Funke G, Hutson RA, Hilleringmann M, Heizmann WR, Collins MD: Corynebacterium lipophiloflavum sp. nov. isolated from a patient with bacterial vaginosis. FEMS Microbiol Lett 1997, 150:219-224.

52. Trost E, Götker S, Schneider J, Schneiker-Bekel S, Szczepanowski R, Tilker A, Viehoever P, Arnold W, Bekel T, Blom J, et al: Complete genome sequence and lifestyle of black-pigmented Corynebacterium aurimucosum ATCC 700975 (formerly C. nigricans $\mathrm{CN}-1$ ) isolated from a vaginal swab of a woman with spontaneous abortion. BMC Genomics 2010, 11:91.

53. Dusitsin N, Gregoire AT, Johnson WD, Rakoff AE: Histidine in human vaginal fluid. Obstet Gynecol 1967, 29:125-129.

54. Coyle MB, Lipsky BA: Coryneform bacteria in infectious diseases: clinical and laboratory aspects. Clin Microbiol Rev 1990, 3:227-246.

55. NIH HMP Working Group, Peterson J, Garges S, Giovanni M, Mclnnes P. Wang L, Schloss J, Bonazzi V, McEwen J, Wetterstrand K, et al: The NIH human microbiome project. Genome Res 2009, 19:2317-2323.

56. Nielsen H, Engelbrecht J, Brunak S, von Heijne G: A neural network method for identification of prokaryotic and eukaryotic signal peptides and prediction of their cleavage sites. Int J Neural Syst 1997, 8:581-599.

57. Hansmeier N, Chao T-C, Pühler A, Tauch A, Kalinowski J: The cytosolic, cell surface and extracellular proteomes of the biotechnologically important soil bacterium Corynebacterium efficiens YS-314 in comparison to those of Corynebacterium glutamicum ATCC 13032. Proteomics 2006, 6:233-250

58. Krogh A, Larsson B, von Heijne G, Sonnhammer EL: Predicting transmembrane protein topology with a hidden Markov model: application to complete genomes. J Mol Biol 2001, 305:567-580.

59. Clancy KW, Melvin JA, McCafferty DG: Sortase transpeptidases: insights into mechanism, substrate specificity, and inhibition. Biopolymers 2010, 94:385-396.

60. Michel JL, Madoff LC, Olson K, Kling DE, Kasper DL, Ausubel FM: Large, identical, tandem repeating units in the $C$ protein alpha antigen gene, bca, of group B streptococci. Proc Natl Acad Sci USA 1992, 89:10060-10064

61. Gravekamp C, Rosner B, Madoff LC: Deletion of repeats in the alpha C protein enhances the pathogenicity of group $B$ streptococci in immune mice. Infect Immun 1998, 66:4347-4354.

62. Stalhammar-Carlemalm M, Areschoug T, Larsson C, Lindahl G: The R28 protein of Streptococcus pyogenes is related to several group B streptococcal surface proteins, confers protective immunity and promotes binding to human epithelial cells. Mol Microbiol 1999, 33:208-219.

63. Rogers EA, Das A, Ton-That H: Adhesion by pathogenic corynebacteria. Adv Exp Med Biol 2011, 715:91-103.

64. Mandlik A, Swierczynski A, Das A, Ton-That H: Corynebacterium diphtheriae employs specific minor pilins to target human pharyngeal epithelial cells. Mol Microbiol 2007, 64:111-124.

65. Hett EC, Chao MC, Deng LL, Rubin EJ: A mycobacterial enzyme essential for cell division synergizes with resuscitation-promoting factor. PLOS Pathog 2008, 4:e1000001

66. Ott L, Holler M, Gerlach RG, Hensel M, Rheinlaender J, Schäffer TE, Burkovski A: Corynebacterium diphtheriae invasion-associated protein (DIP1281) is involved in cell surface organization, adhesion and internalization in epithelial cells. BMC Microbiol 2010, 10:2.

67. Marchler-Bauer A, Lu S, Anderson JB, Chitsaz F, Derbyshire MK, DeWeeseScott C, Fong JH, Geer LY, Geer RC, Gonzales NR, et al: CDD: a Conserved Domain Database for the functional annotation of proteins. Nucleic Acids Res 2011, 39:D225-229.

68. Kolodkina V, Denisevich T, Titov L: Identification of Corynebacterium diphtheriae gene involved in adherence to epithelial cells. Infect Genet Evol 2011, 11:518-521.

69. Linder R, Bernheimer AW: Oxidation of macrophage membrane cholesterol by intracellular Rhodococcus equi. Vet Microbiol 1997, 56:269-276.

70. Brzostek A, Dziadek B, Rumijowska-Galewicz A, Pawelczyk J, Dziadek J: Cholesterol oxidase is required for virulence of Mycobacterium tuberculosi. FEMS Microbiol Lett 2007, 275:106-112.
71. MacLachlan J, Wotherspoon AT, Ansell RO, Brooks CJ: Cholesterol oxidase: sources, physical properties and analytical applications. I Steroid Biochem Mol Biol 2000, 72:169-195.

72. Mao C, Obeid LM: Ceramidases: regulators of cellular responses mediated by ceramide, sphingosine, and sphingosine-1-phosphate. Biochim Biophys Acta 2008, 1781:424-434.

73. Nieuwenhuizen WF, van Leeuwen S, Jack RW, Egmond MR, Gotz F: Molecular cloning and characterization of the alkaline ceramidase from Pseudomonas aeruginosa PA01. Protein Expr Purif 2003, 30:94-104.

74. Hube B, Stehr F, Bossenz M, Mazur A, Kretschmar M, Schäfer W: Secreted lipases of Candida albicans: cloning, characterisation and expression analysis of a new gene family with at least ten members. Arch Microbiol 2000, 174:362-374.

75. Akoh CC, Lee GC, Liaw YC, Huang TH, Shaw JF: GDSL family of serine esterases/lipases. Prog Lipid Res 2004, 43:534-552.

76. Goo KS, Sim TS: Designing new beta-lactams: implications from their targets, resistance factors and synthesizing enzymes. Curr Comput Aided Drug Des 2011, 7:53-80

77. Lavollay M, Arthur M, Fourgeaud M, Dubost L, Marie A, Riegel P, Gutmann L, Mainardi JL: The beta-lactam-sensitive D, D-carboxypeptidase activity of Pbp4 controls the L, D and D, D transpeptidation pathways in Corynebacterium jeikeium. Mol Microbiol 2009, 74:650-661.

78. Hooper DC: Mechanisms of fluoroquinolone resistance. Drug Resist Updat 1999, 2:38-55.

79. Eguchi H, Kuwahara T, Miyamoto T, Nakayama-Imaohji H, Ichimura M, Hayashi T, Shiota H: High-level fluoroquinolone resistance in ophthalmic clinical isolates belonging to the species Corynebacterium macginleyi. J Clin Microbiol 2008, 46:527-532.

80. Sierra JM, Martinez-Martinez L, Vazquez F, Giralt E, Vila J: Relationship between mutations in the gyrA gene and quinolone resistance in clinical isolates of Corynebacterium striatum and Corynebacterium amycolatum. Antimicrob Agents Chemother 2005, 49:1714-1719.

81. Cattoir V, Lesprit P, Lascols C, Denamur E, Legrand P, Soussy CJ, Cambau E: In viv selection during ofloxacin therapy of Escherichia coli with combined topoisomerase mutations that confer high resistance to ofloxacin but susceptibility to nalidixic acid. J Antimicrob Chemother 2006, 58:1054-1057.

82. Tauch A, Pühler A, Kalinowski J, Thierbach G: Plasmids in Corynebacterium glutamicum and their molecular classification by comparative genomics. J Biotechnol 2003, 104:27-40.

83. Tauch A, Krieft S, Kalinowski J, Pühler A: The 51,409-bp R-plasmid pTP10 from the multiresistant clinical isolate Corynebacterium striatum M82B is composed of DNA segments initially identified in soil bacteria and in plant, animal, and human pathogens. Mol Gen Genet 2000, 263:1-11.

84. Sonnen $H$, Thierbach G, Kautz S, Kalinowski J, Schneider J, Pühler A, Kutzner HJ: Characterization of pGA1, a new plasmid from Corynebacterium glutamicum LP-6. Gene 1991, 107:69-74.

85. Williams LE, Detter C, Barry K, Lapidus A, Summers AO: Facile recovery of individual high-molecular-weight, low-copy-number natural plasmids for genomic sequencing. Appl Environ Microbiol 2006, 72:4899-4906.

86. Chattoraj DK: Control of plasmid DNA replication by iterons: no longer paradoxical. Mol Microbiol 2000, 37:467-476.

87. Roberts MC: Update on macrolide-lincosamide-streptogramin, ketolide, and oxazolidinone resistance genes. FEMS Microbiol Lett 2008, 282:147-159.

88. Weisblum B: Insights into erythromycin action from studies of its activity as inducer of resistance. Antimicrob Agents Chemother 1995, 39:797-805.

89. Tauch A, Bischoff N, Brune I, Kalinowski J: Insights into the genetic organization of the Corynebacterium diphtheriae erythromycin resistance plasmid pNG2 deduced from its complete nucleotide sequence. Plasmid 2003, 49:63-74.

90. Schiller J, Groman N, Coyle M: Plasmids in Corynebacterium diphtheriae and diphtheroids mediating erythromycin resistance. Antimicrob Agents Chemother 1980, 18:814-821.

91. Ross Jl, Eady EA, Carnegie E, Cove JH: Detection of transposon Tn5432mediated macrolide-lincosamide-streptogramin B (MLSB) resistance in cutaneous propionibacteria from six European cities. J Antimicrob Chemother 2002, 49:165-168. 
92. Rosato $A E$, Lee $B S$, Nash KA: Inducible macrolide resistance in Corynebacterium jeikeium. Antimicrob Agents Chemother 2001, 45:1982-1989.

93. Mankin AS: Macrolide myths. Curr Opin Microbiol 2008, 11:414-421.

94. Shen T, Jia $P, N a S$, Men D: Determination of nucleotide sequence of Corynebacterium plasmid pXZ10145. Chin J Biotechnol 1993, 9:171-178.

95. Chiou CS, Jones AL: Expression and identification of the strA-strB gene pair from streptomycin-resistant Erwinia amylovora. Gene 1995, 152:47-51.

96. McManus PS, Stockwell VO, Sundin GW, Jones AL: Antibiotic use in plant agriculture. Annu Rev Phytopathol 2002, 40:443-465.

97. Shaw K, Rather PN, Hare RS, Miller GH: Molecular genetics of aminoglycoside resistance genes and familial relationships of the aminoglycoside-modifying enzymes. Microbiol Rev 1993, 57:138-163.

98. Vakulenko SB, Mobashery S: Versatility of aminoglycosides and prospects for their future. Clin Microbiol Rev 2003, 16:430-450.

99. Ploy MC, Lambert T, Couty JP, Denis F: Integrons: an antibiotic resistance gene capture and expression system. Clin Chem Lab Med 2000, 38:483-487.

100. Partridge SR, Tsafnat G, Coiera E, Iredell JR: Gene cassettes and cassette arrays in mobile resistance integrons. FEMS Microbiol Rev 2009, 33:757-784.

101. Wachino J, Doi Y, Yamane K, Shibata N, Yagi T, Kubota T, Ito H, Arakawa Y: Nosocomial spread of ceftazidime-resistant Klebsiella pneumoniae strains producing a novel class a beta-lactamase, GES-3, in a neonatal intensive care unit in Japan. Antimicrob Agents Chemother 2004, 48:1960-1967.

102. Doi Y, Shibata N, Shibayama K, Kamachi K, Kurokawa H, Yokoyama K, Yagi T, Arakawa Y: Characterization of a novel plasmid-mediated cephalosporinase (CMY-9) and its genetic environment in an Escherichia coli clinical isolate. Antimicrob Agents Chemother 2002, 46:2427-2434.

103. Parent R, Roy PH: The chloramphenicol acetyltransferase gene of $\mathrm{Tn} 2424$ : a new breed of cat. J Bacterio/ 1992, 174:2891-2897.

104. Nesvera J, Hochmannova J, Patek M: An integron of class 1 is present on the plasmid pCG4 from gram-positive bacterium Corynebacterium glutamicum. FEMS Microbiol Lett 1998, 169:391-395.

105. Tauch A, Götker S, Pühler A, Kalinowski J, Thierbach G: The 27.8-kb Rplasmid pTET3 from Corynebacterium glutamicum encodes the aminoglycoside adenyltransferase gene cassette aadA9 and the regulated tetracycline efflux system Tet 33 flanked by active copies of the widespread insertion sequence IS6100. Plasmid 2002, 48:117-129.

106. Rosander A, Connolly E, Roos S: Removal of antibiotic resistance genecarrying plasmids from Lactobacillus reuteri ATCC 55730 and characterization of the resulting daughter strain, L. reuteri DSM 17938. Appl Environ Microbiol 2008, 74:6032-6040.

107. Connell SR, Tracz DM, Nierhaus KH, Taylor DE: Ribosomal protection proteins and their mechanism of tetracycline resistance. Antimicrob Agents Chemother 2003, 47:3675-3681

108. Princivalli MS, Palmieri C, Magi G, Vignaroli C, Manzin A, Camporese A, Barocci S, Magistrali C, Facinelli B: Genetic diversity of Streptococcus suis clinical isolates from pigs and humans in Italy (2003-2007). Euro Surveill 2009, 14:19310.

109. Billington SJ, Songer JG, Jost BH: Widespread distribution of a tet(W) determinant among tetracycline-resistant isolates of the animal pathogen Arcanobacterium pyogenes. Antimicrob Agents Chemother 2002, 46:1281-1287.

110. Kazimierczak KA, Flint HJ, Scott KP: Comparative analysis of sequences flanking tet $(\mathrm{W})$ resistance genes in multiple species of gut bacteria. Antimicrob Agents Chemother 2006, 50:2632-2639.

111. Oliva B, Gordon G, McNicholas P, Ellestad G, Chopra I: Evidence that tetracycline analogs whose primary target is not the bacterial ribosome cause lysis of Escherichia coli. Antimicrob Agents Chemother 1992, 36:913-919.

112. Rasmussen B, Noller HF, Daubresse G, Oliva B, Misulovin Z, Rothstein DM, Ellestad GA, Gluzman Y, Tally FP, Chopra I: Molecular basis of tetracycline action: identification of analogs whose primary target is not the bacterial ribosome. Antimicrob Agents Chemother 1991, 35:2306-2311.

113. Nesin M, Svec P, Lupski JR, Godson GN, Kreiswirth B, Kornblum J, Projan SJ: Cloning and nucleotide sequence of a chromosomally encoded tetracycline resistance determinant, tet(M), from a pathogenic, methicillin-resistant strain of Staphylococcus aureus. Antimicrob Agents Chemother 1990, 34:2273-2276.
114. Roberts MC, Leonard RB, Briselden A, Schoenknecht FD, Coyle MB: Characterization of antibiotic-resistant Corynebacterium striatum strains. J Antimicrob Chemother 1992, 30:463-474.

115. Campanile F, Carretto E, Barbarini D, Grigis A, Falcone M, Goglio A, Venditti M, Stefani S: Clonal multidrug-resistant Corynebacterium striatum strains, Italy. Emerg Infect Dis 2009, 15:75-78.

116. Tauch A, Bischoff N, Pühler A, Kalinowski J: Comparative genomics identified two conserved DNA modules in a corynebacterial plasmid family present in clinical isolates of the opportunistic human pathogen Corynebacterium jeikeium. Plasmid 2004, 52:102-118.

117. Sambrook J, Fritsch EF, Maniatis T: Molecular cloning A laboratory manual. 2 edition. Cold Spring Harbour: Cold Spring Harbour Laboratory Press; 1989.

118. Keilhauer C, Eggeling L, Sahm H: Isoleucine synthesis in Corynebacterium glutamicum: molecular analysis of the ilvB-ilvN-ilvC operon. J Bacteriol 1993, 175:5595-5603

119. Hopwood D: Genetic Manipulation of Streptomyces: A Laboratory Manual New York: Cold Spring Harbor Laboratory Press; 1985.

120. Carver T, Thomson N, Bleasby A, Berriman M, Parkhill J: DNAPlotter: circular and linear interactive genome visualization. Bioinformatics 2009, 25:119-120.

121. Schneider J, Vorhölter FJ, Trost E, Blom J, Musa YR, Neuweger H, Niehaus K, Schatschneider S, Tauch A, Goesmann A: CARMEN - Comparative analysis and in silico reconstruction of organism-specific metabolic networks. Genet Mol Res 2010, 9:1660-1672.

122. Clinical and Laboratory Standards Institute: Methods for Antimicrobial Dilution and Disk Susceptibility Testing of Infrequently Isolated or Fastidious Bacteria: Approved Guideline. Methods for Antimicrobial Dilution and Disk Susceptibility Testing of Infrequently Isolated or Fastidious Bacteria. Wayne 2006.

123. Tauch A, Kirchner O, Wehmeier L, Kalinowski J, Pühler A: Corynebacterium glutamicum DNA is subjected to methylation-restriction in Escherichia coli. FEMS Microbiol Lett 1994, 123:343-347.

124. Tauch A, Kirchner O, Löffler B, Götker S, Pühler A, Kalinowski J: Efficient electrotransformation of Corynebacterium diphtheriae with a minireplicon derived from the Corynebacterium glutamicum plasmid pGA1. Curr Microbiol 2002, 45:362-367.

125. Brune I, Jochmann N, Brinkrolf K, Hüser AT, Gerstmeir R, Eikmanns BJ, Kalinowski J, Pühler A, Tauch A: The IcIR-type transcriptional repressor $\mathrm{LtbR}$ regulates the expression of leucine and tryptophan biosynthesis genes in the amino acid producer Corynebacterium glutamicum. $J$ Bacteriol 2007, 189:2720-2733.

doi:10.1186/1471-2164-13-141

Cite this article as: Schröder et al:: Complete genome sequence, lifestyle, and multi-drug resistance of the human pathogen Corynebacterium resistens DSM 45100 isolated from blood samples of a leukemia patient. BMC Genomics 2012 13:141.

\section{Submit your next manuscript to BioMed Central and take full advantage of:}

- Convenient online submission

- Thorough peer review

- No space constraints or color figure charges

- Immediate publication on acceptance

- Inclusion in PubMed, CAS, Scopus and Google Scholar

- Research which is freely available for redistribution

Submit your manuscript at www.biomedcentral.com/submit
C Biomed Central 